Jarl G. Kallberg

Crocker H. Liu

Stern School of Business, New York University

Paolo Pasquariello

Ross School of Business, University of Michigan

\section{An Examination of the Asian Crisis: Regime Shifts in Currency and Equity Markets*}

\section{Introduction}

To most observers the Asian currency crisis began in July 1997 with the devaluation of the Thai baht. It spread quickly through East Asia, although with widely differing intensity and duration, and eventually affected the global economy, pushing several emerging countries into a deep recession. However, prior to this date, a number of the Asian economies had already begun to stagnate. As well, several countries experienced further currency crises into 1998 and suffered a decline during the summer of that year in correspondence with the ruble crisis and huge capital flight out of most emerging markets.

* We thank the editor, Albert Madansky, and two anonymous referees for many suggestions, which have substantially improved this paper. We are very grateful to Robert Dittmar for detailed comments and suggestions. We also acknowledge the comments of Viral Acharya, Edward Altman, Yakov Amihud, Tony Kao, Kanak Patel, Bertrand Renaud, Vijay Singal, and other participants in seminars at the 1999 AREA/AREUEA conference in Maui, the 1999 NYU Conference on Risk and Return Management for Insurance Companies, the 2000 Indiana University Sixth Biennial Conference on Financial Crises, the 2001 AFA Annual Meeting in New Orleans, and the 2002 EFMA Annual Meeting in London. Please address comments to the authors through email: jkallber(âstern.nyu.edu, cliu $\bar{\omega}_{\text {stern. nyu. }}$ edu, and ppasquar@bus.mich.edu, respectively. The usual disclaimer applies.

(Journal of Business, 2005 , vol. 78, no. 1)

(c) 2005 by The University of Chicago. All rights reserved. $0021-9398 / 2005 / 7801-0006 \$ 10.00$
Using a nonparametric technique for the identification of regime shifts, we find breaks in the structural relations between currency and equity returns and return volatility in Indonesia, Malaysia, the Philippines, South Korea, Taiwan, and Thailand during the recent Asian crisis. Volatility breaks occurred in late 1994 and 1997 , while return breaks were concentrated in early 1998 . After the estimated breaks, many Asian equity markets became more responsive to the volatility of the corresponding domestic exchange rate. We find that information spillover and portfolio rebalancing, rather than common information shocks, represented major channels for the transmission of breaks across countries. 
Many popular explanations for the Asian crisis emphasize the relationship between equity and currency markets in each country (see Corsetti, Pesenti, and Roubini 1998 for an overview). A collapse in equity values led to an outflow of foreign investment, which exerted downward pressure on the domestic currency. From another perspective, currency devaluation, perhaps triggered by speculation, disrupted the domestic financial sector, then the entire domestic economy, finally bringing the equity market to a collapse. The magnitude of the losses in equity and currency markets during this period was in fact remarkable. Between June 1997 and September 1998, the Indonesian rupiah depreciated versus the U.S. dollar by $79 \%$, while Indonesia's equity index declined by $56 \%$. The corresponding figures for Malaysia and the Philippines are $61 \%$ and $40 \%$, and $67 \%$ and $34 \%$, respectively (see Lin and Kuo 2000).

One of the most significant questions raised by the events of 1997 and 1998 is the extent to which the crisis was the result of natural dependencies rather than an example of an irrational or "herding" phenomenon. Therefore, the purpose of this study is to examine how equity and currency markets reacted during this crisis. Many studies of financial crises focus on the correlations among countries' equity and currency returns before and after a crisis. If the correlations are significantly higher, a contagion effect is indicated, as in Bertero and Mayer (1990), and Lee and Kim (1993). But, as Forbes and Rigobon (2002) point out, this approach is flawed, since the standard tests of increases in covariance are biased toward acceptance. Furthermore, Andersen, Bollerslev, Diebold, and Labys (1999) show that, in foreign exchange markets, high volatilities are associated with high correlations. A common empirical approach in the literature uses ARCH or GARCH specifications for volatility and return time series; for example, see Hamao, Masulis, and $\mathrm{Ng}$ (1990) and Karolyi and Stulz (1996). These applications use high-frequency data to test for cointegration and typically focus on the transmission of volatility across markets.

Our approach is different. We posit a simple, reduced-form structural relation between the equity and currency markets in each of six Asian countries: Indonesia, Malaysia, the Philippines, South Korea, Taiwan, and Thailand. We select these countries for our study not only because all of them were financially integrated (to various degrees) by the early 1990 s and arguably experienced the greatest extent of fmancial, economic, and political turmoil during 1997 and 1998, but also because each of them, prior to the crisis, maintained a pegged currency regime. More specifically, we estimate a linear relation between the equity returns in a given country and leads and lags of the corresponding domestic currency returns (relative to the U.S. dollar). We estimate a model for returns and volatility separately in each country. We then test for a regime shift in these relations. When a shift occurs, the nonparametric 
technique we use, developed by Bai, Lumsdaine, and Stock (1998), allows us to determine confidence intervals around the break dates and perform statistical inference into the nature of the break with minimal restrictions on the underlying data generation process.

Our data set comprises monthly return observations. The choice of lower-frequency data mitigates the potential impact of infrequent trading effects on the statistical inference, as suggested by Harvey (1995). If there is a regime break in our selected time frame, then we can assume that a structural shift occurred between these markets. Analyzing the nature of this shift can help us understand its dynamics more precisely. For example, the shift could be the result of an adjustment in the means, a change in the lead-lag relation, or the like. If instead no shift occurred between 1997 and 1998 , then we assume that the crisis event is a manifestation of natural dependencies across these markets.

The patterns of potential regime breaks we observe during the Asian crisis allow us to address a second issue: Are these shocks consistent with the theoretical modeling of how various types of information events affect returns and volatility? The speculative trading model of Fleming, Kirby, and Ostdiek (1998) can be applied to portfolio allocation in multiple foreign markets. Their study provides a framework for analyzing how structural breaks in a single market can spill over to others in two possible ways. First, a common information shock generates trading activity and volatility in each market simultaneously. Second, an information shock alters expectations in one market, resulting in investors adjusting their holdings in other markets. Portfolio rebalancing occurs because of the existence of correlations between returns, that is, because of the ensuing changes in hedging demand. Fleming et al. call the latter case "information spillover." Therefore, our second goal includes testing whether the structural breaks occur simultaneously across all countries in our sample or in sequence. If all markets experience structural breaks simultaneously, then common information shocks predominate. If, instead, the timing of regime shifts differs across markets in various countries, then cross-country information spillover effects are significant.

A further aspect of this issue is to compare the timing of shocks to volatility and returns. It has long been argued in the financial literature that price and return volatility are related to the arrival of information. Merton (1980) develops a diffusion model showing that the variance of prices equals the rate of information flow. Shalen (1993) proves that new information generates speculative trade because it modifies the dispersion of beliefs among traders. ' Under the assumption that information can arrive at different times to different types of traders, Hirshleifer, 
Subrahmanyam, and Titman (1994) demonstrate that profit-taking behavior and herding should be more apparent in stocks that have more late-informed traders. If the spillover of information is not instantaneous, we test if shocks in volatility will affect future returns. This issue is part of the extensive literature dealing with return predictability. In a study of the U.S. stock market, French, Schwert, and Stambaugh (1987) found evidence that a positive relation between expected equity volatility and risk premiums leads to a negative relation between the unpredicted component of volatility and excess returns. French et al. argue that, if risk premiums are positively related to the predicted component of market volatility, then a larger-than-predicted volatility will not only result in an upward revision of future volatility but increase the discount rate for future cash flows. The persistence of this shock in the predicted volatility depends on the particular return model adopted. The higher discount rate reduces the current stock price if cash flows do not adjust. Subsequent research (for example, Haugen, Talmor, and Torous 1991 or Brown, Harlow, and Tinic 1993) shows that future stock returns are positively correlated to current shifts in volatility. In our empirical setting, we wish to determine whether or not information shocks lead to shifts in the structure of the volatility relation before or after they affect the return structure. Providing an answer to these questions is of interest not only to researchers aiming to understand how financial crises propagate but also to policy makers and regulators hoping to predict and prevent future crises.

We find that regime shifts in the hypothesized return and volatility relations did indeed occur in each of the six Asian countries in our data set over the interval 1994-98. The estimated regime shifts between equity and currency returns differ widely, both in timing and nature, from country to country. We show that shifts in volatility lead shifts in returns. While most regime shifts in returns take place almost a year after the currency crisis, many volatility breaks occur around the crisis period. The shocks in the return relations affect Malaysia and Thailand first, then the rest of Asia. Volatility breaks are instead concentrated in the fall of 1994 for Malaysia, Taiwan, and Thailand and in the last months of 1997 for the other countries in our sample. Our results also indicate that, after the estimated regime shifts occurred, most Asian equity markets became more responsive to the volatility of the corresponding domestic exchange rate. The sequential nature of breaks in the structural relationship between currency and equity market returns and volatility in various Asian countries is consistent with information spillover effects.

Such evidence suggests not only that breaks in volatility anticipated breaks in returns but also that volatility shocks in one country may have affected the posited relations between equity and currency markets in other countries during the crisis. To test for this possibility, we estimate 
the impact of the break event in each country on the reduced-form volatility relation of other countries. If information spillover were at least partially responsible for the propagation of the event from one country to another, we would expect the statistical power of such structural relations to improve by including dummies for break dates in other countries. We find some evidence of information spillover across Indonesia, the Philippines, and South Korea between 1997 and 1998, when past regime shifts in the linear relation between their domestic equity and currency return volatility appear to have induced a statistically and economically significant decline in equity returns.

Finally, we attempt to link those estimated regime shifts to the movements of foreign capital using data on the flows of funds in each of the countries in this study. In particular, we seek to gain some insight into how the actions of international investors, specifically capital flight, influenced the structure of Asian currency and equity markets around the time of the crisis. To that purpose, we first test for whether the observed sequence of structural breaks and the clustering in the estimated regime breaks can be explained by portfolio rebalancing or the "herding" behavior of foreign investors. We then develop a Poisson regression model to analyze whether changes in the flows of funds were responsible for the observed clustering in regime shifts.

Our analysis provides further evidence that information spillover or herding effects generate the observed return and volatility shocks among countries. We show that portfolio rebalancing was a major channel for transmitting information shocks across markets during 1997 but not in 1998 (when the highest degree of herding occurred and most of the breaks in returns were instead observed). We also demonstrate that the expected number of return and return volatility break events per period was greater, and the clustering of those break events more likely, when signed herding was more intense (i.e., when more equity markets were simultaneously experiencing withdrawals).

The organization of the paper is as follows. Section II reviews the literature on the East Asian crisis that relates to our analysis. Section III illustrates the statistical methodology. Section IV describes the data sets and examines our first set of results. In section V, we study the relation between herding behavior and cross-country spillover. Section VI concludes.

\section{Explaining Financial Crises}

Financial crises have generated many economic explanations and models; Calomiris (1995) presents an overview. Several plausible reasons for the Asian crisis and its propagation across world economies have emerged. The disruptive actions of hedge funds, high volumes of foreign currency borrowing by Asian firms, mishandling by the IMF and 
the Asian governments, and excessive risk-taking by banks and local entrepreneurs are among the most frequently cited.

Many economists, such as Corsetti et al. (1998) and Allen and Gale (2000), have focused on the country "domino effect," that is, the impact of the occurrence of a financial crisis in one country on other, not necessarily contiguous, markets. Others, like Forbes and Rigobon (2002), downplay the contagion story and attribute the outcomes of the crisis to existing intermarket correlations. For example, as real estate markets plummeted, banks suffered enormous losses due to their exposure to real estate developers. These losses then spread to the rest of the financial sector (see Renaud 1997, 1999).

Foreign exchange plays a central role in each of these possible explanations. Hence, the Asian financial crisis is usually labeled a currency crisis, as in Park and Lee (2001). Choe, Kho, and Stulz (1999) argue that the currency crisis led to problems in the banking sector, as a response to deteriorating expectations about future economic activity. They document the extremely low returns to Asian banks between January 1997 and July 1998. High levels of dollar-denominated corporate borrowing further magnified the crippling role of foreign exchange during the crisis, as emphasized by Thurow (1998). ${ }^{2}$ Currency crises are often modeled on the basis of restrictive assumptions about government strategies (for example, focusing on "unilateral pegs" and bilateral country structures). Buiter, Corsetti, and Pesenti (1998) analyze these flaws. One rationale underlying the currency and equity market contagion effect is that trade linkages provide a channel for the spread of financial problems, as in Glick and Rose (1999) and Dasgupta (2000).

Crises, like bank runs, can also contain a self-fulfilling element. In this case, Obstfeld (1998) states that a sharp transition from equilibrium to a crisis state is more likely than a smooth decline of the domestic economy. Allen and Gale (2000) model this effect. Because liquidity preference shocks are imperfectly correlated across geographical regions, banks hold interregional claims on other banks to provide insurance against these shocks. A small liquidity preference shock in one region can then spread throughout the economy. Allen and Gale find that the likelihood and intensity of contagion is highly dependent on the completeness of the market for interregional claims. Related to these models is the idea that the spread of financial crises is magnified because of incomplete information, as in Calvo and Mendoza (1997). Thus, a crisis in one country can signal information about the fmancial condition of other countries that share underlying regional factors and trade patterns. The widespread withdrawal of foreign funds, which

2. Thurow (1998) observes that, by the end of 1997, most Korean private companies appeared to have borrowed some $\$ 160$ billion in foreign curency, half in short-term loans. 
creates pressure on the domestic currencies and interest rates, would then follow. ${ }^{3}$

Research that examines the transmission of information shocks across markets is relevant to understanding financial crises. The most significant paper for our study is Fleming et al. (1998), who analyze volatility shocks across debt, equity, and money markets. Their work extends the single-asset, mean-variance model of Tauchen and Pitts (1983) to multiple markets and investigates empirically the effects of cross-market dependencies. As previously mentioned, Fleming et al.'s main goal was to investigate volatility linkages of two distinct types. In the first case, a common information shock affects traders' expectations in each market simultaneously. Reacting to this shock, traders adjust their speculative demand across markets. In the second case (information spillover), an information shock perturbs expectations in one market, resulting in investors rebalancing their portfolios across other markets. With frictionless markets, the information spillover effect is complete and instantaneous. Under these circumstances, we could not distinguish empirically between shocks attributable to common information and an information spillover effect. However, practical considerations (e.g., market frictions) mitigate the intensity and speed of the information spillover effect and permit its empirical identification. Transaction costs and institutional constraints, such as position and capital limits, restrict the trading activity of portfolio managers for both speculative and hedging purposes. These factors further reduce investors' ability to trade simultaneously in disparate markets. Differences in market depth may also reduce the speed with which an information shock spills over to other markets.

In the next section, we model empirically the interaction among equity and currency markets as a (linear) structural relation between equity and currency returns and between their corresponding volatilities. We then test whether a break occurred in any of these relations during the Asian crisis. The chronology of the estimated regime shifts will help us determine which kind of information shock affected the Far East markets in 1997 and 1998.

\section{Methodology: Testing for Regime Breaks}

In this section, we describe the empirical method we use to test for the existence of shocks in the structural relation between equity and currency returns and equity and currency volatility. By observing the

3. In 1997, the prime minister of Malaysia, Dr. Mahathir Mohamed, called hedge fund managers the "highwaymen" of the global econony. See Chancellor (2000). In Kallberg, Liu, and Pasquariello (2002), we explore in greater depth the role played by capital flight in the Asian crisis. 
timing and the intensity of the breaks in the hypothesized structural relations between returns and volatilities, we can test several implications of the crisis models discussed in the previous section. Although the problem of detecting break dates in economic and financial time series has received increasing attention in the literature, formal measures of the precision of these estimates could not be obtained. ${ }^{4}$ The estimation of a confidence interval around the break date is important to economists because it incorporates a measure of sampling uncertainty in the analysis.

In this paper, we adopt the statistical method of Bai, Lumsdaine, and Stock (1998), as it permits statistical inference about regime breaks, including interval estimation of the break date, with minimal restrictions on the underlying data generation process (DGP). In fact, Bai et al.'s nonparametric technique searches for a single break in univariate or multivariate time series models (with or without stationary regressors) assuming only that the DGP is a stationary vector autoregression (VAR) before and after the break and specifies asymptotic confidence intervals for the estimated break point.

We use this approach to test for regime shifts in the hypothesized linear relation between equity and currency returns and equity and currency return volatility for each country. ${ }^{5}$ We start by applying the technique to a reduced-form model for returns. The model uses month $t$ equity index returns denominated in local currency as the dependent variable. The independent variables are the currency returns in each of the five months $t-2$ to $t+2$ (to account for possible lead-lag relations) and the equity return in month $t-1$ (to account for first-order autocorrelation in returns). We perform a similar analysis on monthly volatility, estimated using a 12 -month rolling window. ${ }^{6}$ We have the following equation:

$y_{t}=\mu+A y_{t-1}+\sum_{i=1}^{5} b_{i} x_{t+i-3}+d_{t}(k)\left[\lambda+\alpha y_{t-1}+\sum_{i=1}^{5} \beta_{i} x_{t+i-3}\right]+\varepsilon_{t}$,

with $d_{t}(k)$ equal to 1 if $t$ is greater than or equal to $k$, and zero otherwise. ${ }^{7}$

Here, $k$ is a potential break date, $y_{t}$ is the equity index return for a certain country in month $t$, and $x_{t}$ is the corresponding currency return

4. See, for example, Penon (1989) and Banerjee, Lumsdaine, and Stock (1992).

5. This technique was first applied by Bekaert, Harvey, and Lumsdaine (2002a) to date the integration of world financial markets.

6. Officer (1973) and Merton (1980) were the first to use a rolling 12-month standard deviation. Our results are not sensitive to the particular averaging interval.

7. It is important to observe that the preceding lead-lag specification does not necessarily imply a causal relation from the market for the domestic currency to the local equity market, or vice versa, in a country. Indeed, eq. (1) also allows for the possibility that one market reacts to a common information shock faster than the other. 
in month $t$. If we define $S$ as a binary selection matrix with diagonal elements of ones corresponding to the parameters of eq. (1) that are allowed to change, we can write eq. (1) in a stacked form:

$$
y_{t}=V_{t}^{\prime} \hat{v}+d_{t}(k) V_{t}^{\prime} S^{\prime} S \delta+\varepsilon_{t}
$$

with $V_{t}^{\prime}=\left(1, y_{t-1}, x_{t-2}, \ldots, x_{t+2}\right), \vartheta=\left(\mu, A, b_{1}, \ldots, b_{5}\right)^{\prime}$, and $\delta=(\lambda, \alpha$, $\left.\beta_{1}, \ldots, \beta_{5}\right)^{\prime}$. In matrix form this is equivalent to

$$
y_{t}=Z_{t}^{\prime}(k) B+\varepsilon_{t}
$$

where $Z_{t}^{\prime}(k)=\left[V_{t}^{\prime}, d_{t}(k) V_{t}^{\prime} S^{\prime}\right]$ and $B=(\vartheta, S \delta)$.

The model allows a wide range of assumptions about parameter shifts. The model is one of a full structural change if all $(R)$ coeffcients are allowed to change. Then, $S=I_{R}$. If we instead assume that only a subset of the coefficients undergoes a regime shift, then a partial structural model is more appropriate. For example, if we suspect a break only in the intercept, then we assume that only $S(1,1)=1$. As reported in Bai et al. (1998), tests for partial structural changes tend to have more power than those for full structural changes. However, our analysis indicates that the breaks are statistically significant when we use a full structural model rather than simply allowing the intercept to break. A variety of tests for a break based on Wald statistics have been proposed in the literature. For a null hypothesis that $S \delta=0$, for $k=$ $k_{1}{ }^{*}+1, \ldots, T-k_{2}{ }^{*}$, where $k_{1}{ }^{*}$ and $k_{2}{ }^{*}$ are some trimming values, ${ }^{8}$ Bai et al.'s test, which is similar to that of Quandt $(1958,1960)$, considers the maximum of the following $F$ process:

$\hat{F}(k)=T\{R \hat{B}(k)\}^{\prime}\left\{R\left(T^{-1} \sum_{i=1}^{T} Z_{t}(k) \hat{\Sigma}_{k}^{-1} Z_{i}^{\prime}(k)\right)^{-1} R^{\prime}\right\}^{-1}\{R \hat{B}(k)\}$

where $R=[0, S]$ is such that $R B=S \delta$, and $\hat{B}(k)$ and $\hat{\Sigma}_{k}$ are the estimators for $B$ and the residual variance $\sigma_{z}^{2}$, respectively, evaluated under the alternative hypothesis, that is, given $k$. The estimated break date is then $\hat{k}$, the value that maximizes $\hat{F}(k)$ and is statistically significant if $\hat{F}(\hat{k})$ is greater than the corresponding critical value (for the selected significance level). ${ }^{9}$

8. Trimming is necessary for the model of eq. (1) to be full rank before and after any possible break date $k$. Because of the lead-and-lag structure of eq. (1) and the definition of $d_{t}(k)$, the trimming values used in our analysis are $k_{1}{ }^{*}=10$ and $k_{2}{ }^{*}=9$.

9. To compute critical values for the max $\hat{F}(k)$, Bai et al. (1998) suggest approximating the limiting distribution of the $F$ process with partial sums of normal random variables for each possible dimension of the test statistic $\hat{F}(k)$, that is, for the rank of the selected vector $S$. Bekaert et al. (2002a) report one such table with critical values for dimensions up to 68 , which we use for this research. 
When we analyze a time series, if there is in fact a break, then the problem of constructing confidence intervals for the true break dates is not trivial. Various authors have examined this problem under the assumption of independently and identically distributed Gaussian errors. ${ }^{10}$ Bai et al. (1998) instead assume that the disturbances form a sequence of martingale differences with some moment conditions and use limit theorems to construct asymptotic confidence intervals for the true break date, with coverage of at least $100(1-\pi) \%$, of the following form:

$$
\hat{k} \pm c_{\frac{1}{2} \pi}\left[(S \hat{\delta})^{\prime} S\left(\hat{\Sigma}_{k}^{-1} T^{-1} \sum_{t=1}^{T} V_{t} V_{t}^{\prime}\right) S^{\prime}(S \hat{\delta})\right]^{-1}
$$

where $\hat{k}$ and $\hat{\Sigma}_{k}$ are the estimated values for the break date and $\sigma_{\varepsilon}^{2}$, respectively, and $\mathcal{C}_{1 / 2 \pi}$ is the $100(1-\pi / 2)$ th quantile of the Picard (1985) distribution for $\pi=0.05$. . Next, we describe statistically the two regimes identified by the structural break in the return time series. More specifically, we estimate the hypothesized model assuming that $\hat{k}$ is in fact the true break date; that is, we estimate the parameters of the following regression model:

$$
y_{t}=Z_{t}(\hat{k})^{\prime} B+\varepsilon_{t}
$$

Equation (6) allows us to examine the effects of the identified structural break, if any, over the parameters of the structural relations between equity and currency returns.

We then focus on the second moments of returns, by extending the basic model of eq. (1) to the case of equity and currency volatility. More precisely, we search for breaks in a structural relation between monthly rolled volatility for the available series of equity returns and the corresponding monthly rolled volatility series for currency returns. We calculate the rolled volatility as a moving standard deviation of

10. For a review of the available literature on the topic, see Bai et al. (1998).

11. Bai et al. (1998) investigate some of the finite sample properties of these test statistics. Using Monte Carlo simulations on $\mathbf{I}(0)$ and $\mathbf{I}(1)$ models, they show that the tests perform adequately, in terms of size and power, under the null hypothesis of no break and under the alternative hypothesis of a break in the mean of the DGP. Bai et al. also observe that, for a fixed break magnitude, the confidence interval does not depend on the sample size and, in particular, does not shrink for bigger sample sizes. Nonetheless, their results suggest that the asymptotic confidence intervals tend to be too tight and the performance of all the univariate intervals improves substantially when $T$ is increased. Further exploration of such issues for more general structural break specifications, available in Bekaert et al. (2002a), confirms that the size properties of the Wald test statistics are satisfactory in univariate models regardless of whether exogenous regressors are included in the analysis. 
12 monthly returns for the equity $\left(\sigma_{y}\right)$ and currency $\left(\sigma_{x}\right)$ index returns. ${ }^{12}$ The proposed model is now

$$
\sigma_{y t}=\mu+A \sigma_{y t-1}+b \sigma_{x t}+d_{t}(k)\left[\lambda+\beta \sigma_{x t}\right]+\varepsilon_{t} .
$$

Finally, as for returns in eq. (6), we estimate eq. (7) for each country at the measured break date to examine the effects of the regime shift over such reduced-form relation for volatility. ${ }^{13}$

As previously mentioned, many studies in the growing literature on financial crises use ARCH and GARCH models to analyze the behavior of volatility through time. GARCH models are especially attractive because of their ability to capture the time-varying nature of volatility with a limited number of coefficients. However, this approach is much less successful in capturing regime shifts in economic time series due to low-probability events, such as financial crises (see Susmel 2000 for a review). To overcome this shortcoming, Hamilton and Susmel (1994) extended ARCH specifications to account explicitly for potential structural changes in the underlying DGP. Edwards and Susmel $(2000,2001)$ use a variant of this methodology, known as SWARCH, to test whether higher-volatility regimes and increased codependence of those volatility regimes across countries characterize weekly interest rate and equity time series for a sample of Asian and Latin American markets. Their results indicate that volatility comovements are more likely among stock markets than among money markets. The SWARCH setting, however, is highly parametric, for it requires conditional normality of residuals and the formulation of a specific probability law (e.g., a Markov chain), causing the economy to switch regimes. Inference therefore becomes more problematic, since tests of the null hypothesis of no breaks are simultaneously tests of the validity of these assumptions. The technique of Bai et al. (1998), employed in this paper, allows us to test whether a reduced-form relation between equity and currency return volatility underwent a statistically significant break over the selected interval while, at the same time, imposing the simplest structure possible on the DGP.

One of the main goals of this paper is to test whether the events of 1997 and 1998 affected the interaction between equity and currency markets. The specifications selected to that purpose in eqq. (1) and (7) result from a balance between the statistical significance of the estimated coefficients,

12. For this case, the trimming values we adopted are $k_{1}^{*}=5$ and $k_{2}^{*}=4$.

13. Note that, by construction, the rolled volatility series has positive serial correlation. We take this into account by including a lagged term in the regression model. However, since the focus of ow analysis is on breaks in the relation between markets and most of the series' persistence is induced by the way it is computed, we do not allow the serial correlation coefficient to vary in eq. (7). Allowing the persistence term to vary after date $\hat{k}$ results in mostly insignificant postbreak coefficient changes and does not affect the inference based on the reported Wald statistics. 
economic rationale, and data availability constraints. Nevertheless, as emphasized by Rigobon (2001), stock market returns and exchange rate data, especially at high frequencies, appear to be "plagued with simultaneous equations, omitted variables, conditional and unconditional heteroskedasticity, serial correlation, non-linearity and non-normality problems." However, autocorrelations in our data set of equity and currency return series (not reported here) are either small or not statistically significant at the monthly frequency we use in the analysis. Moreover, the nonparametric technique devised by Bai et al. has the attractive feature of not requiring normality in the residuals from eqq. (1) and (7).

Albeit with these caveats, testing for the existence and timing of volatility and return shocks, that is, for breaks in the posited linear relations, can help us shed some light on whether events observed in Asia in 1997 and 1998 are attributable to either common information shocks or information spillover from one country to another. If common information shocks are associated with the Asian crisis, then we should see concurrent regime shifts in volatility and returns across countries. On the other hand, if the timing of these regime shifts differs across countries, then we can attribute this to information spillover effects.

\section{Empirical Results}

\section{A. Data}

We use monthly time series of currency and equity returns in our analysis of Indonesia, Malaysia, the Philippines, South Korea, Taiwan, and Thailand. We assume that the exchange rate of each local currency relative to the dollar is the key exchange rate variable. Therefore, the monthly currency returns are the spot rates that correspond to the noon buying rate for cable transfers payable in foreign currencies, as recorded by the Federal Reserve Bank of New York every business day. For each of the six markets, we use the major equity index in local currency to calculate a monthly time series of local returns: JCI Jakarta Composite Index, EMAS Equity Index, PSE Index, Kospi 200, the Thailand Stock Exchange Index, and the TWSE Stock Index. Monthly equity indexes for each country are from Bloomberg.

A variety of reasons justify the composition of our data set. First, according to Bekaert et al. (2002a), the capital markets of the selected countries had already moved from financially segmented to integrated regimes by the end of the $1980 \mathrm{~s}$ and the beginning of the $1990 \mathrm{~s}$, earlier than our sample periods. ${ }^{14}$ Therefore, if no statistically significant

14. This is true regardless of whether the date of each country's integration with world markets in Bekaert et al. (2002a) is measured using endogenously estimated dates or dates of official capital market reforms (official liberalization dates, introduction of ADRs, introduction of country funds). 
regime break can be found between 1997 and 1998, we can interpret the events accompanying the Asian crisis as manifestations of natural dependencies across those markets, consistent with the regimes induced by the earlier process of economic and financial integration. Second, these countries arguably suffered the greatest degree of economic, financial, and political turmoil during 1997 and 1998. A brief chronology of the crisis is reported in table 1 . These economies, except Taiwan, were explicitly entitled by the Asian Development Bank (ADB) to access emergency funding facilities made available by Japan in the fall of 1998 (the "New Miyazawa Initiative") in recognition of the severe impact of the currency crisis on their economic and financial systems. ${ }^{15}$ Third, all those countries were unilaterally pegged to the U.S. dollar by relatively tight bands of fluctuation around the time of the Asian crisis. ${ }^{16}$ Thailand abandoned its fixed exchange rate regime on July 2,1997 . Indonesia gave up its enlarged currency band on August 14, 1997. The Indonesian rupiah crashed soon afterward. South Korea renounced battling the increasing selling pressure on the won in November 1997, and so did Malaysia. The Philippines and Taiwan were also hit by the crisis, although less severely. In the Philippines, the central bank was forced to relax its previously successful band of fluctuations for the peso by the end of July 1997. Taiwan at first was able to fend off expectations of increased depreciation through its central bank's policy of active foreign exchange intervention. Therefore, the country initially appeared unaffected by the economic instability undermining the rest of the region. However, on October 17,1997 , Taiwan decided to adopt a floating exchange rate regime, and the new Taiwan dollar subsequently fell by $30 \%$ versus the U.S. dollar.

Many analysts and economists seem to agree that Taiwan's economy paid a very high price for the comparative resilience shown throughout 1997 and 1998, in particular in the domestic financial markets, where the steep rise of short-term interest rates and the loss of foreign reserves were accompanied by a severe (albeit lagging) decline of the stock market. Indeed, while many other Asian equity markets were plummeting, the TWSE Stock Index instead rose by $13.15 \%$ in 1997 , before eventually falling by more than $21 \%$ in 1998 . Investigating the potential role of portfolio rebalancing in explaining these disparities and the occurrence of potential "information spillover" events from one market to another is an objective of this research.

15. The intemational political isolation of Taiwan from the rest of Asia may explain its exclusion from the "New Miyazawa Initiative".

16. Grier and Grier (2001) find that currency depreciation and equity price declines were more pronounced than what could have been justified by existing macroeconomic fiundamentals in developing countries that started 1997 with an exchange rate peg. 
TABLE 1 A Chronology of the Asian Crisis, 1997-99

Date Event

May 1997

July 2,1997

End of July 1997

August 14, 1997

Fall 1997 (1)

Fall $1997(2)$

October 17, 1997

October 20, 1997

October 20, 1997

October 24, 1997

October 27, 1997

November 1997

November 17, 1997

November 18, 1997

November 22, 1997

December 1997

December 4, 1997

July 6,1998

July 20, 1998

August 17, 1998

September 1, 1998

September 2, 1998

September 23, 1998

October 15, 1998

Fall 1998

January 10, 1999

January 13,1999
The Thai baht comes under strong depreciation pressure

Devaluation of the Thai baht

The Philippines central bank relaxes its fluctuation band for the peso

Indonesia abandons the rupiah trading band

The IMF offers U.S. \$1 billion to the Philippines to rescue the peso

An aid fund of U.S. $\$ 16$ billion is granted by the IMF to Thailand

Taiwan's central bank adopts a clean floating foreign exchange regime

The Hong Kong dollar (HKD) falls victim to speculation

The Taiwanese dollar (NTD) depreciates by $5 \%$ against the U.S. dollar

The overnight interest rate in Hong Kong soars from $5 \%$ to $300 \%$

The Hang Seng index plunges; panic selling in New York and Europe

Indonesia is granted U.\$. $\$ 23$ billion by the IMF

South Korea abandons its defense of the won

U.S. and Japan meet with Southeast Asian countries in Manila

Korean government formally asks the IMF for bail out

IMF lawnches the biggest international aid plan in history for Korea

Markets question the plan; the won falls to nearly 2000 for a U.S. dollar dollar

Salomon Brothers dismantles its bond arbitrage desk

First Wall Street Journal headlines on LTCM losses

Russian effective default and ruble devaluation

Malaysia introduces capital controls

LTCM shareholder letter, announcing the fund's collapse, is issued

LTCM recapitalization

Intermeeting Federal Reserve rate cut

Japan launches the "Miyazawa Initiative" to rescue East Asian countries

China refuses to help foreign creditors of GITIC; markets disrupted

Fears of debt crisis in China sweep through Hong Kong: Brazil devalues the real

NoTE.-This table, from the authors, Bank for International Settlements (1999), and Kaminsky and Reinhant, (2000), reports selected significant economic, political, and financial events that occured between 1997 and the first three nonths of 1999 .

As mentioned earlier, the choice of monthly data is also not casual and is consistent with previous applications of the technique used in this paper to detect the occurrence of structural breaks in economic and financial time series (e.g., Bai et al. 1998 and, more recently, Bekaert et al. 2002a, 2002b). Employing weekly or even daily equity and currency data for the identification of structural breaks in fact raises concerns related to the possibility of biases induced by infrequent or 
nonsynchronous trading. Although the trading activity of many of the emerging markets is surprisingly intense, Harvey (1995) suggests that it might be appropriate to use monthly rather than weekly time series to mitigate the possible influences of these biases and short-term noise on the resulting statistical inference. Furthermore, as reported by Bai et al. (1998) (and summarized in note 11 of Section III), Monte Carlo analysis of the finite sample performance of the proposed estimator for $\hat{k}$ reveals little or no change in the estimated confidence intervals for increased frequency and constant sample length $T$; substantial improvements in the precision in the estimated break date appear to be obtained only for constant frequency and increased $T$.

\section{B. Basic Statistics}

Table 2 presents summary statistics for each country. Sample periods are of different length, due to data availability constraints, but they all end in March 1999. Mean returns and sample volatilities reveal a wide disparity across the region. Mean monthly equity returns are negative in the Philippines $(-0.29 \%)$ and Thailand $(-0.67 \%)$. Table 2 also reports (not surprisingly) negative returns on currencies over this period. Correlation matrices for currency and equity returns and their corresponding volatility time series (not reported here) characterize the interaction among the six countries we consider.

The correlations for equity returns are mostly positive, ranging between 0.306 and 0.691 . The currency return correlations are similar, although somewhat lower than those obtained for equity index returns. These facts seem to indicate that the markets and the asset classes in our study are only moderately correlated. ${ }^{17}$ Hence, there appear to be exante hedging and portfolio rebalancing opportunities for fund managers investing in the region.

Volatility correlations across the six countries tend to be much more significant (and higher) than the return correlations, ranging from 0.507 to 0.969 . We also observe a very wide dispersion of values, which suggests that the lead-lag relations among these countries are complex. Correlations between equity and currency returns are all quite low, from a minimum of -0.206 to a maximum of 0.408 . This confirms our previous observation that diversification effects should be strong and the existence of common factors in these returns is not apparent. As before, correlations between equity and currency volatility show higher values than those between the corresponding return time series. Most of the countries have volatility correlations higher than 0.636 .

17. This conclusion is even stronger if we take into account that those matrices are affected by the increase in correlation that followed the events of 1997 and 1998 . For an analysis of the behavior of correlations in Asia before and after 1997, see Baig and Goldfajn (1998). 


\section{TABLE 2 Descriptive Statistics}

\begin{tabular}{|c|c|c|c|c|c|c|c|}
\hline \multirow[b]{2}{*}{ Coumtries } & \multicolumn{2}{|c|}{ Equity Returns } & \multicolumn{2}{|c|}{ Currency Returns } & \multicolumn{2}{|c|}{ Flows of Funds } & \multirow[b]{2}{*}{ Sample Size } \\
\hline & Mean & Std Dev & Mean & Std Dev & Mean & Std Dev & \\
\hline Indonesia & $.06 \%$ & $11.88 \%$ & $-5.56 \%$ & $25.05 \%$ & 60.67 & 146.88 & Jan 96-Мar 99 \\
\hline Malaysia & $.19 \%$ & $10.19 \%$ & $-.62 \%$ & $3.40 \%$ & 86.52 & 648.09 & Nov 92-Mar 99 \\
\hline Philippines & $-.29 \%$ & $10.06 \%$ & $-.91 \%$ & $3.77 \%$ & 154.15 & 184.61 & Nov 94-Mar 99 \\
\hline South Korea & $.21 \%$ & $10.52 \%$ & $-.55 \%$ & $5.01 \%$ & 229.77 & 445.79 & Jan $90-$ Mar 99 \\
\hline Tajwan & $1.02 \%$ & $9.38 \%$ & $-.34 \%$ & $1.99 \%$ & 100.78 & 335.04 & Apr 93-Mar 99 \\
\hline Thailand & $-.67 \%$ & $11.84 \%$ & $-.62 \%$ & $5.23 \%$ & 64.55 & 432.00 & Mar 93-Mar 99 \\
\hline
\end{tabular}

Note.-This table displays descriptive statistics (mean and standard deviation) for time series of local equity indexes and currency returns and flows of funds for each of the countries included in the study. Equity returns in local currency are computed from local equity indexes' monthly time series obtained from Bloombers. Currency returns are calculated from the exchange rate versus the U.S. dollar. The minus sign represents devaluation of the local currency. Curency data are fron the Federal Reserve Bank of New York. Flows of funds are in millions of U.S. dollars and calculated as the difference between the total foreign purchases and sales of domestic stocks in each month of the sample. 
TABLE 3 Analysis of Structural Breaks

\begin{tabular}{llllll}
\hline Country & 2.5th Percentile & Median & 97.5th Percentile & Max Wald & $p$-Value \\
\hline \multicolumn{7}{c}{ A. Analysis of Equity Indexes Monthly Returns } \\
\hline Indonesia & May 1998 & Jun 1998 & & \\
Malaysia & Oct 1997 & Feb 1998 & Jun 1998 & 24.19 & $<.05$ \\
Philippines & Feb 1998 & Apr 1998 & May 1998 & 35.64 & $<.01$ \\
South Korea & Dec 1997 & Mar 1998 & May 1998 & 47.33 & $<.01$ \\
Taiwan & Jan 1994 & Feb 1994 & May 1998 & 26.52 & $<.05$ \\
Thailand & Jan 1998 & Mar 1998 & Feb 1994 & 23.93 & $<.05$ \\
\hline
\end{tabular}

B. Analysis of Equity Indexes Monthly Return Volatility

\begin{tabular}{llllll}
\hline Indonesia & May 1997 & Jun 1997 & Jun 1997 & 70.70 & $<.01$ \\
Malaysia & Jun 1994 & Oct 1994 & Jan 1995 & 23.56 & $<.01$ \\
Philippines & Jul 1998 & Aug 1998 & Aug 1998 & 63.61 & $<.01$ \\
South Korea & Sep 1997 & Nov 1997 & Dec 1997 & 17.67 & $<.01$ \\
Taiwan & Sep 1994 & Oct 1994 & Oct 1994 & 32.55 & $<.01$ \\
Thailand & Sep 1994 & Oct 1994 & Oct 1994 & 21.22 & $<.01$
\end{tabular}

Note.-This table reports estimated break dates $\vec{k}$ for the structural relation between equity and currency returns (panel A):

$$
v_{f}=\mu+A v_{f-1}+\sum_{i=1}^{5} b_{j} x_{j-3}+d_{f}(k)\left[\lambda+\alpha y_{t-1}+\sum_{i=1}^{5} \beta_{i} x_{t+i-3}\right]+\varepsilon_{s}
$$

and between equity and currency return volatility (panel B):

$$
\sigma_{y \mathrm{r}}=\boldsymbol{\mu}+A \sigma_{y f-1}+b \sigma_{s t}+d_{s}(h)\left[\lambda+\beta \sigma_{s t}\right]+\hat{\varepsilon}_{t}
$$

respectively. The Median colunn shows the estimated break date $\hat{k}$, computed using the Wald statistic $F$ described in eq. (4). For botl eqq. (1) and (7), we test the null hypothesis that the postbreak coefficient changes are not significantly different from zero, that is, no break occurred in the sample period, by comparing the maxinum value in the estimated time series $\hat{F}(k)$ to the $5 \%$ quantile of its limiting distribution. The null hypothesis is rejected when the maximum value for $\hat{F}(h)$, reported in the Max Wald colunu, is lower than the critical value for the selected significance level. Bekaent et al. (2002a) compute a table with critical values for max $\hat{F}(k)$ (for dimensions up to 68), approxinating the limiting distribution of the $F$ process with partial sums of normal random variables for each possible dimension of the test statistic $\hat{F}(k)$. From such table, we use the asymptotic $1 \%(5 \%)$ critical value of 27.02 (22.21) for eq. (1) (where seven parameters are allowed to break) and of 16.37 for eq. (7) (where two parameters are allowed to break). The 2.5 th and 97.5 th Percentile columns display estimated lower and upper bands, respectively, for the confidence intervals for the "true" break dates, computed with quantiles of the Picard (1985) distribution.

a Significant at the $5 \%$ level (for a critical value of 22.21 ).

b Significant at the $1 \%$ level (for a critical value of 27.02 ) or less.

- Significant at the $1 \%$ level (for a critical value of 16.37 ) or less.

\section{Analvzing Regime Shifts}

We start by testing for breaks in the assumed structural relationships between local equity returns and local currency returns (table 3, panel A) and between the volatility of local equity returns and the volatility of local currency returns (table 3, panel B). As an example of the analysis underlying table 3 , we report in figure 1 the time series of equity and currency indexes (figure 1a), their rolled volatility series (figure 1b), and the corresponding Wald statistics (figures $1 \mathrm{c}$ and $1 \mathrm{~d}$ ), computed 

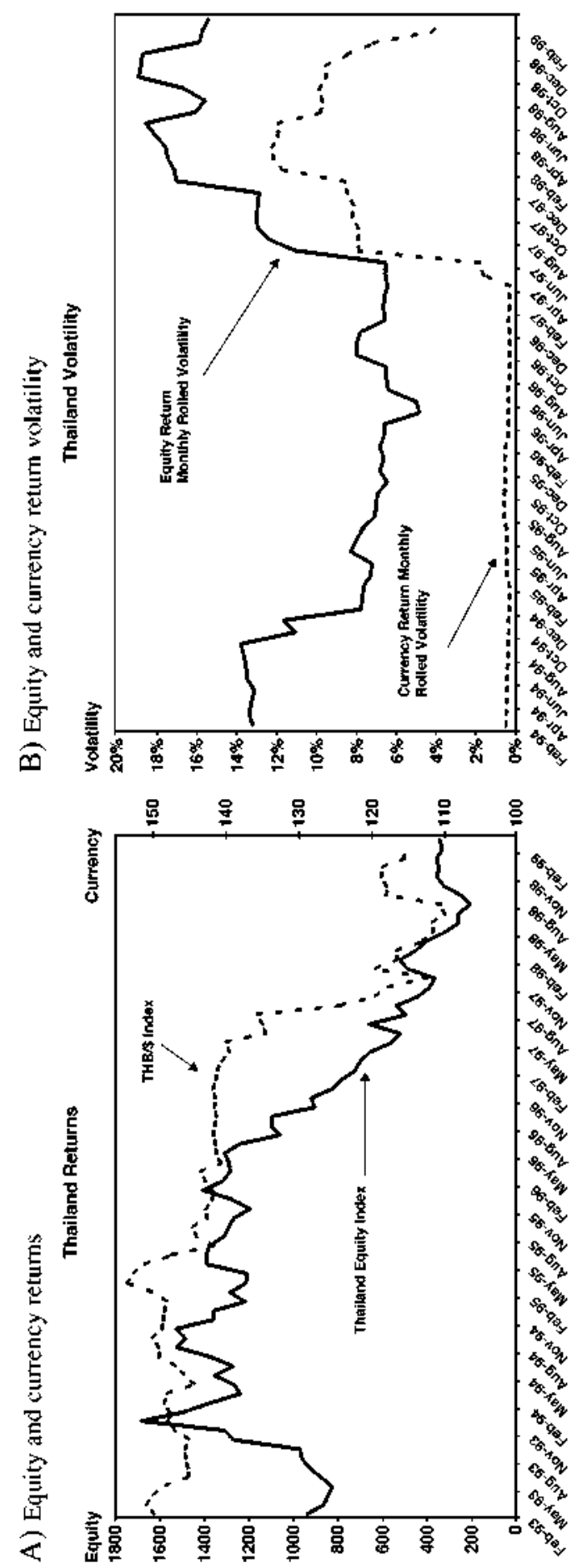
C) Search for a break in the return relation

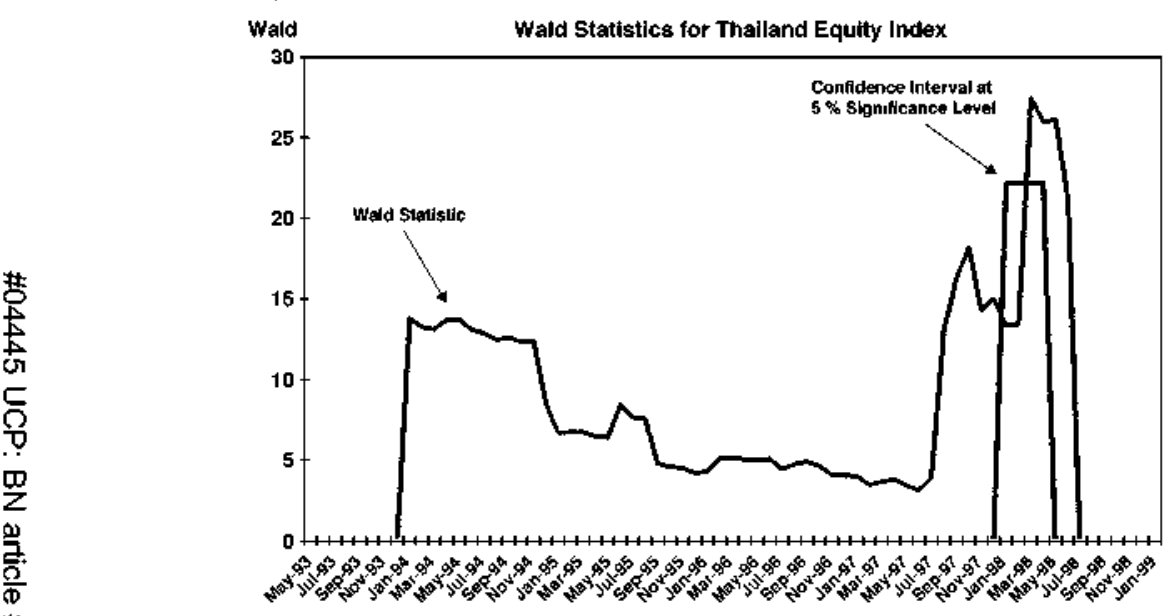

D) Search for a break in the return volatility relation

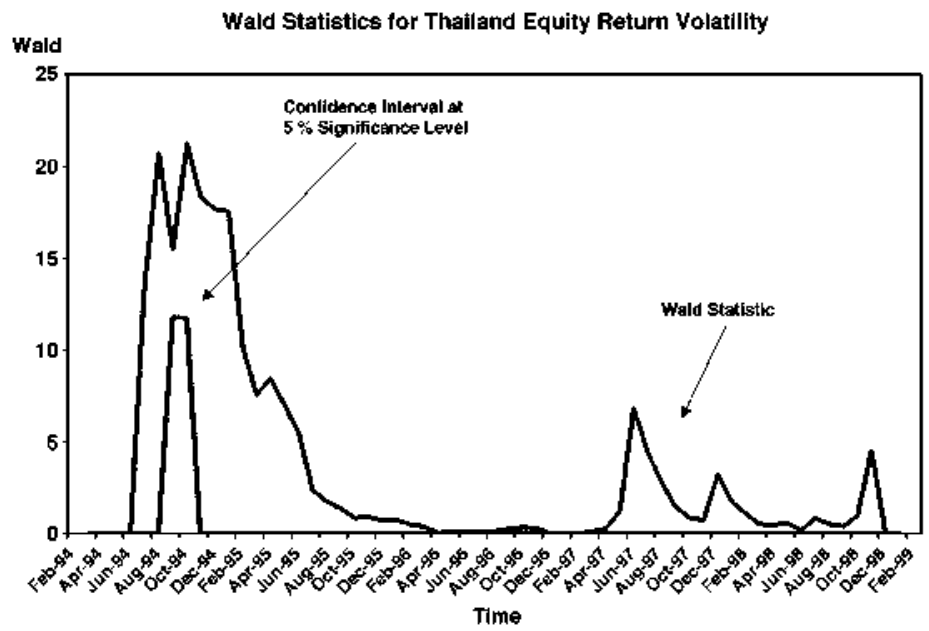

Fig. 1.-Search for a break in the structural relations between equity and currency returns and return volatility: Thailand. Figure la displays the monthly time series for the Thailand Stock Exchange Index (on the left axis) and a $\$ /$ baht currency index (on the right axis) constructed with January 1971 as base date (100). Lower values of the currency index represent a weaker baht relative to the U.S. dollar. Figure 1b shows the time series of rolled volatility for both equity and currency returns. Rolled volatility is computed from monthly return time series using a 12-month rolling window. Figures $1 \mathrm{c}$ and $\mathbf{1 d}$ report (on the left axis) the monthly time series of the Wald statistic $F(k)$ to test for a break in the structural relation between equity and currency returns (eq. [1]) and equity and currency volatility (eq. [7]), respectively. The 5\% confidence intervals (plotted at the $5 \%$ significance level for the Wald statistic) around the date $\hat{k}$ that maximizes $\hat{F}(k)$ over the sample interval are computed according to eq. (5). 
according to eq. (4) in section III, for Thailand. Figures 2 and 3 display the confidence intervals at the $5 \%$ level around those estimated break dates $\hat{k}$, ranked in order of increasing statistical significance, over two time intervals: March-December 1997 and January-October 1998. These two intervals correspond to most of the observed break dates for equity versus currency returns (figures $2 a$ and $3 a$ ) and equity versus currency return volatility figures $2 b$ and $3 b$.

Table 3 (and figures 2 and 3 ) contain the main features of our analysis of regime shifts in returns and return volatility. The table reports the median break point date and its associated significance. For the relations between equity and currency return in table 3 , panel $\mathrm{A}$, we find that all the countries in our sample experience a statistically significant regime shift (at the 5\% level). More important, all the shifts (except Taiwan) occur from February to June 1998. The shocks appear to affect Malaysia and South Korea first, then quickly move to the other countries. For example, the shift in the parameters of eq. (1) for Thailand is statistically significant in March 1998, in the aftermath of the devaluation of the baht but before the Russian default (see table 1). Our results also offer some support to the notion (supported, among others, by Wu 1998) that financial instability in Taiwan during the Asian crisis was less acute than in the rest of the region.

The picture offered by the analysis of the relation between equity and currency return volatility in table 3 , panel $B$ is very different. The estimated regime shifts are more dispersed in time than in the case of returns. Structural breaks in eq. (7) affect Malaysia, Taiwan, and Thailand in October 1994. Around the time of the currency crisis, regime shifts involve Indonesia and South Korea. Finally, in August 1998, the Philippines undergoes a switch.

An analysis of the pre- and postbreak regressions, given in tables 4 and 5, illuminates the nature of these regime shifts and of the lead-lag relations in these countries. To correct for heteroscedasticity and autocorrelation in the residuals of regressions (1) and (7), the statistical significance of the coefficients is measured using Newey-West standard errors. As discussed in Section II, the postbreak coefficients represent incremental changes in the prebreak coefficients. Table 4 refers to the regime shift analysis for volatility reported in table 3 , panel $\mathrm{B}$. The posited structural relations fit the data relatively well: adjusted $R^{2}$ values range from $83 \%$ (Taiwan) to $97 \%$ (Malaysia). The most complete regime shift seems to have occurred in Malaysia, Taiwan, and Thailand, where both the intercept term $(\mu)$ and the coefficient for the contemporaneous relationship between equity and currency return volatility $(A)$ in eq. (7) experience a statistically significant change.

The most startling result from Table 4 is the uniformity across countries in the sign of $\beta$, the change in the contemporaneous linear relation between equity and currency return volatility after a break occurred. 
A) Sequence of return breaks

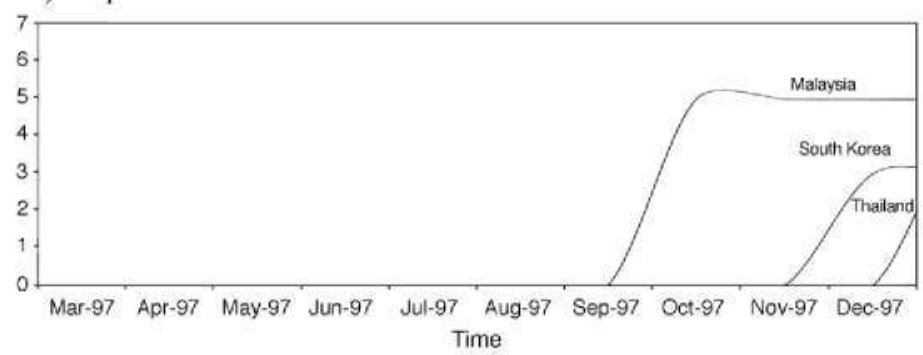

B) Sequence of votality breaks

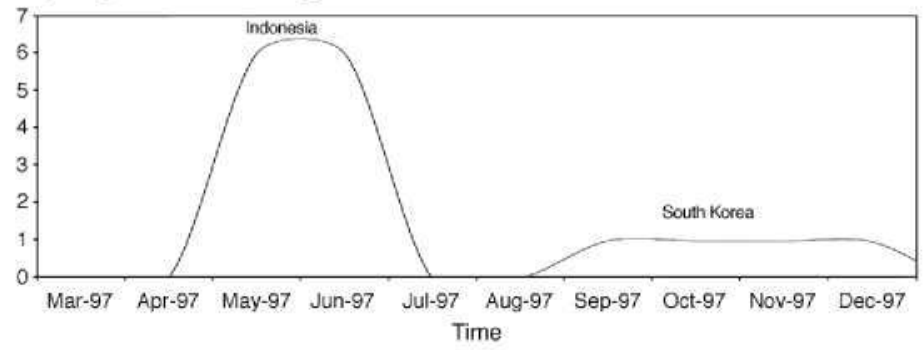

C) Sequence of flows of funds

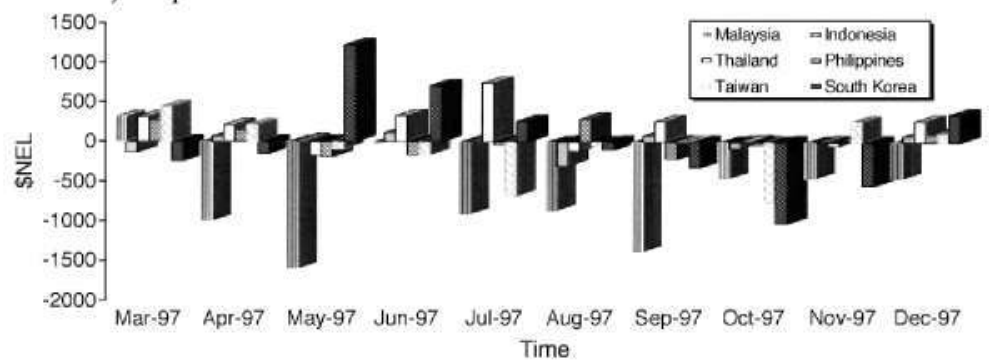

FIG. 2.-Flows of funds, return, and volatility breaks in East Asia: March 1997January 1998 . Figures $2 \mathrm{a}$ and $2 \mathrm{~b}$ display confidence intervals at the $5 \%$ significance level around the estimated break date $\hat{k}$, that is, the one that maximizes the Wald statistic $\hat{F}(k)$ over the sample interval, for the structural relations between equity and currency return and volatility, respectively. The confidence intervals are computed according to Bai et al. (1998). The confidence interval measure of 6 (left axis) is associated with the country for which we measure the most significant $\hat{F}(\hat{k})$ in the sample. The confidence interval measure of 1 (left axis) is associated with the country for which we measure the least significant $\hat{F}(\hat{k})$ in the sample. Figure 2c reports monthly flows of funds data for the six countries in our sample: Indonesia, Malaysia, the Philippines, South Korea, Taiwan, and Thailand. Flows of funds are in millions of U.S. dollars and are calculated as the difference between the total foreign purchases and sales of domestic stocks in each month of the sample. 
A) Sequence of return breaks

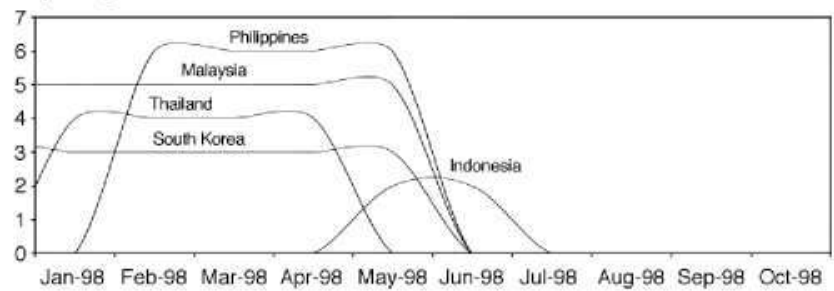

B) Sequence of votality breaks

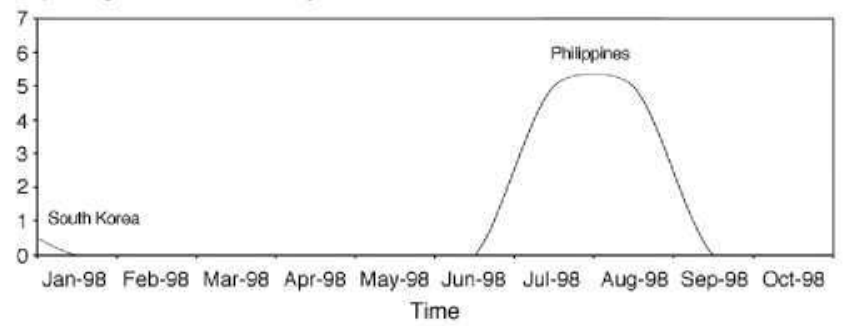

C) Sequence of flows of funds

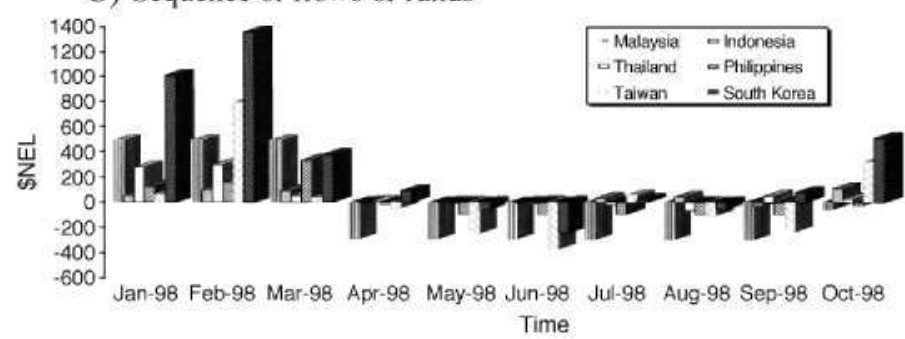

FIg. 3.-Flows of funds, return, and volatility breaks in East Asia: AprilDecember 1998. Figures $3 \mathrm{a}$ and $3 \mathrm{~b}$ display confidence intervals at the $5 \%$ significance level around the estimated break date $\hat{k}$, that is, the one that maximizes the Wald statistic $\hat{F}(k)$ over the sample interval, for the structural relations between equity and currency return and volatility, respectively. The confidence intervals are computed according to Bai et al. (1998). The confidence interval measure of 6 (left axis) is associated with the country for which we measure the most significant $\hat{F}(\hat{k})$ in the sample. The confidence interval measure of 1 (left axis) is associated with the country for which we measure the least significant $\hat{F}(\hat{k})$ in the sample. Figure $3 \mathrm{c}$ reports monthly flows of funds data for the six countries in our sample: Indonesia, Malaysia, the Philippines, South Korea, Taiwan, and Thailand. Flows of funds are in millions of U.S. dollars and are calculated as the difference between the total foreign purchases and sales of domestic stocks in each month of the sample. 
TABLE 4 Break in the Structural Relation between Equity and Currency Return Volatility

\begin{tabular}{lccccccc}
\hline & & \multicolumn{3}{c}{ Prebreak Coefficients } & & \multicolumn{2}{c}{ Postbreak Coufficients } \\
\cline { 3 - 4 } \cline { 7 - 8 } Country & $R_{a}^{2}$ & Intercept & $X$ & $Y-1$ & & $\Delta$ Intercept & $\Delta X^{-}$ \\
\hline Indonesia & $92.39 \%$ & $.076^{\mathrm{b}}$ & $-8.371^{\mathrm{b}}$ & $.627^{\mathrm{b}}$ & & $-.031^{\mathrm{b}}$ & $8.402^{\mathrm{b}}$ \\
Malaysia & $96.73 \%$ & $.016^{\mathrm{b}}$ & .817 & $.735^{\mathrm{b}}$ & & -.009 & $-.220^{\mathrm{b}}$ \\
Philippines & $93.60 \%$ & $.017^{\mathrm{b}}$ & $.204^{\mathrm{b}}$ & $.721^{\mathrm{b}}$ & & -.003 & .403 \\
South Korea & $94.34 \%$ & $.022^{\mathrm{b}}$ & $-.006^{\mathrm{b}}$ & .685 & & .005 & .309 \\
Taiwan & $82.86 \%$ & $.055^{\mathrm{b}}$ & $-1.503^{\mathrm{b}}$ & .724 & & $-.037^{\mathrm{b}}$ & 1.680 \\
Thailand & $95.27 \%$ & $-.056^{\mathrm{b}}$ & $-2.012^{\mathrm{b}}$ & $.650^{\mathrm{b}}$ & & $-.034^{\mathrm{b}}$ & 2.393 \\
\hline
\end{tabular}

Note.-This table displays regression coefficients estimated at the break date $h$ for the structural relation between equity and curency retum volatility

$$
\sigma_{y f}=\mu+A \sigma_{y f-1}+b \sigma_{x f}+d_{f}(k)\left[\lambda+\beta \sigma_{x t}\right]+\varepsilon_{j} .
$$

The first colunn of the table reports the conesponding adjusted regression $R^{2}, R_{\alpha,}^{2}$, for each of the countries in the sample. The three prebreak coefficient columns display the estimated coefficients in the hypothesized structural relationship before the break occurred. We identify the break dates $\hat{k}$ through the Wald Statistic described in eq. (4). Break dates for each of the countries in our sample are collected in table 3, panel $B$. The two postbreak coefficient columns show the change $(\Delta)$ in the structural coefficients after the break occurred. To correct for heteroscedasticity and autocorrelation in the residuals of this regression, statistical significance of the coefficients is measured using Newey-West standard errors.

Significant at the $10 \%$ level.

b Significant at the $5 \%$ level or less.

Most of the coefficient changes are positive, and many of them are statistically significant. This indicates that, following the estimated regime shifts, equity markets tend to become more responsive to the volatility in the corresponding domestic exchange rate. However, because the breaks occur quite late in our sample period, only few of the coefficients are statistically significant. In table 5, which reports parameter estimates for shifts in the return relations, we observe less pronounced structural shifts than the ones recorded for the volatility relations. The adjusted $R^{2}$ values now range from $37 \%$ (for Taiwan) to $63 \%$ (Philippines), with a much lower average. Again, since many of the regime breaks in returns take place by the end of our sample period (but also because of the presence of multicollinearity), some of the individual coefficients' changes have weak statistical significance and do not suggest any consistent interpretation. ${ }^{18}$

18. This issue arises because, when the Wald statistic identifies a break late in the sample period, there are fewer observations with which to estimate the seven postshift coefficient changes in eq. (1). Indeed, in owr analysis, the breaks in the hypothesized structural relation between equity and currency returns occur in the first few months of 1998 for five of the six countries in the sample. The problem is somewhat less serious in the case of eq. (7), where there are just two postbreak parameters to estimate. In addition, multicollinearity affecting the many explanatory variables in eq. (1) might also obscure their individual contribution to the fit. In short, the resulting postshift estimates for the parameters in eq. (1) may be statistically and economically insignificant, even if the joint effect of the break dummies is significant. Therefore, these coefficients are not reported in table 5 but are available from the authors on request. 
TABLE 5

Break in the Structural Relation between Equity and Currency Returns

\begin{tabular}{|c|c|c|c|c|c|c|c|c|}
\hline Country & $R_{a}^{2}$ & Intercept & $x^{-}$ & $Y-1$ & $x^{-}-1$ & $x^{-}-2$ & $x^{-}+1$ & $X+2$ \\
\hline Indonesia & $41.88 \%$ & .002 & $-.094^{b}$ & -.136 & .014 & $-135^{b}$ & $.129^{b}$ & $.140^{b}$ \\
\hline Malaysia & $42.57 \%$ & .013 & -.701 & -.055 & 1.128 & .514 & $.639^{b}$ & .313 \\
\hline Philippines & $62.66 \%$ & .009 & -.166 & .037 & .756 & $-.984^{b}$ & $1.043^{b}$ & .240 \\
\hline South Korea & $44.79 \%$ & $.001_{\mathrm{b}}$ & $.632^{b}$ & $-.067 \mathrm{~b}$ & $-.991^{b}$ & -.217 & $.354^{6}$ & $.410^{b}$ \\
\hline Taiwan & $26.72 \%$ & $.207^{b}$ & $7.580^{\mathrm{a}}$ & $-.296^{\circ}$ & $2.899^{\mathrm{b}}$ & $13.159^{\circ}$ & $11.089_{\mathrm{b}}^{\mathrm{b}}$ & $-16.505_{b}^{b}$ \\
\hline Thailand & $29.58 \%$ & .003 & -.517 & -.084 & .289 & -.211 & $.742^{\circ}$ & $.359^{\circ}$ \\
\hline
\end{tabular}

Ni)TE.-This table displays regression coefficients estimated at the break date $\hat{k}$ for the structural relation between equity and currency returns

$$
v_{t}=\mu_{l}+A v_{t-1}+\sum_{j=1}^{5} b_{j} x_{t i-3}+d_{f}(\hat{k})\left[\lambda+\alpha y_{t-1}+\sum_{j=1}^{5} \beta_{j} x_{t+i-3}\right]+\hat{\varepsilon}_{r} .
$$

The first column of the table reports the corresponding regression adjusted $R^{2}, R_{u}^{2}$, for each of the countries in the sample. The columns display the estimated prebreak coefficients in the hypothesized structural relationship before the break occurred. The postbreak coefficients are not reported but are avalable from the authors on request. We identify the break dates $\hat{k}$ througli the Wald statistic described in eq. (4). Break dates for each of the counties in our sample are collected in table $\hat{3}$, panel A. Because the breaks in the hypothesized structural relation between equity and currency returns occur late in the sample for five of the six countries in the sample and the interaction among the explanatory variables may obscure their individual contibutions to the fit even if their joint effect is significant, several of the resulting postshift estimates for the parameters in eq. (1) are either statistically or economically insignificant. Hence, those estimates are not reported here but are available from the authors on request. To correct for heteroscedasticity and autocorrelation in the residuals of this regression, the statistical significance of the coefficients is measured using Newey-West standard errors.

Significant at the $10 \%$ level.

b Significant at the $5 \%$ level or less. 
In short, tables 3-5 reveal that, for three of the countries in our sample (Indonesia, the Philippines, and South Korea, where the greatest extent of political turmoil ensued from the Asian crisis, the domestic central banks strictly controlled the corresponding currencies, and market regulations were poor or nonexistent), breaks in the reducedform relations described in eqq. (1) and (7) do occur in 1997 and 1998 for both returns and return volatility. Regime shifts in the lead-lag relation between equity and currency returns were registered for Malaysia, Taiwan, and Thailand as well. Nonetheless, for those three countries, breaks in return volatility cluster by the end of 1994, before the Mexican peso crisis. This evidence suggests that the increase in the volatility of stock and currency returns observed in these economies during the Asian turmoil was a manifestation of natural dependencies among the domestic equity and exchange rate markets rather than the result of a sequence of regime shifts in their interaction.

Furthermore, breaks in the hypothesized structural relations between equity and currency return volatility appear to consistently anticipate the corresponding break events in the returns' relations for most of the countries in our sample, even after accounting for the width of the confidence intervals around the estimated dates $\hat{k}$ in table 3 . For instance, in Indonesia, the reduced-form linear relation between the volatility of the domestic stock market and the volatility of the corresponding exchange rate breaks in a statistically significant fashion in June 1997, ahead of the devaluation of the Thai baht and a full month before the local central bank eventually abandoned the rupiah trading band (as reported in table 1). Nonetheless, the relation between the corresponding equity and currency returns does not shift until June 1998, in the aftermath of the Asian crisis and before the Russian default and the subsequent collapse of long-term capital management (LTCM). This evidence is even stronger when we consider that the time series for the volatility of equity and currency returns used in the analysis are rolled 12-month-window moving averages, hence by construction slow in absorbing shocks.

These results are consistent with the empirical findings of Haugen, Talmor, and Torous (1991). In the context of U.S. markets, they show that regime shifts in volatility, whether sudden or protracted over several months, induce adjustments in the level of stock prices and realized returns. An intuitive explanation of this phenomenon is that any information shock that affects the volatility of a single market's equity index returns, the volatility of the exchange rate, or the relation between the two eventually induces a shock in returns through the adjustment of the predicted component of the index volatility itself. Significant crosscountry correlations then channel the information shock that originates in a specific country into other markets. Market frictions, differences in 
economic fundamentals, and constraints to hedging make the spillover phenomenon more or less pronounced. ${ }^{19}$

The sequential nature of the estimated structural breaks appears to suggest that information spillover effects created return and volatility linkages among Asian markets. Information alters expectations in one market and affects returns and volatility in other markets through changes in hedging demand. The effect of these changes is protracted and delayed by the existence of market frictions. In Section V, we test more explicitly for cross-country information spillover and explore in greater detail the potential role of portfolio rebalancing and herding in the transmission of such volatility shocks across East Asia.

\section{Testing for Volatility Spillover}

A substantial issue remains unresolved: Does the observed sequence of structural breaks imply a causal relation from volatility to returns? In their study of the U.S. equity market, French et al. (1987) argue that larger-than-expected shocks to volatility may induce upward revisions of future volatility predictions, eventually increasing risk premiums. We extend the argument of French et al. (1987) to emerging markets, where the foreign investors' component of the total investment is especially significant and the cash flows of export-oriented firms (which typically represent a relevant percentage of the local equity indexes) are affected by fluctuations in local currencies. Unexpected shocks to the volatility of the domestic market index might result from an unexpected shock to the volatility of the local currency equity index, to the volatility of the exchange rate, or to the correlation between the two. For example, an increase in currency volatility makes the cash flows of export-oriented firms more uncertain. Higher equity volatility could instead raise the discount rates for those cash flows. Their combined effect could induce an upward revision of both predicted currency and equity volatility, causing stock prices in local currency to decline and affecting returns in both domestic and foreign currencies.

We study this dynamic interaction between returns and volatility using the timing information on the break events contained in table 3 . The chronology of the structural breaks in volatility allows us to test for the existence of such information spillover by estimating the impact of the break event in country $i$ at time $t$ on the structural relation itself. We use the estimated break dates to test whether the chronologically sequential relation between volatility breaks and return breaks we found

19. The available empirical evidence on the state of the economies involved in the Asian crisis (see Eichengreen, Rose, and Wyplosz 1996 and Corsetti et al. 1998) leads us to exclude the possibility that idiosyncratic shocks occurred in each of the countries for which the Wald statistic of eq. (4) is statistically significant; hence, that such shocks would explain the chronology of regime shifts in the posited reduced-form relations between equity and currency markets (in table 3). 
TABLE 6 Volatility versus Retum Structural Breaks

\begin{tabular}{lccc}
\hline Country & \multicolumn{1}{c}{$R_{a}^{2}$} & Timing & $\gamma$ \\
\hline Indonesia & $40.50 \%$ & B & -0.0370 \\
Malaysia & $45.08 \%$ & BB & $-0.0447 \mathrm{a}$ \\
Philippines & $61.57 \%$ & $\mathrm{~A}$ & -0.0003 \\
South Korea & $44.76 \%$ & $\mathrm{~B}$ & 0.1031 \\
Taiwan & $25.66 \%$ & $\mathrm{~A}$ & -0.0163 \\
Thailand & $34.13 \%$ & $\mathrm{BB}$ & -0.0676 \\
\hline
\end{tabular}

Note.-This table displays the results of tests for the chronologically sequential relation between equity volatility breaks and equity return breaks in each country. We estimate the following regression:

$$
v_{s}=\mu^{b}+A y_{f-1}+\sum_{j=1}^{S} b_{j} x_{f-3}+d_{s}(\hat{k})\left[\lambda+\alpha y_{f-1}+\sum_{j=1}^{s} \beta_{i} x_{f+i-3}\right]+\hat{c}_{f}+\gamma d_{s}\left(\hat{k}_{\mathrm{vOL}}\right),
$$

where $d_{t}\left(\hat{k}_{\text {YoL }}\right)$ is equal to one when $t$ is higher than or equal to the lower bound of the confidence interval for the corresponding volatility structural break found in table 3 and zero otherwise. The first column of the table shows the regression adjusted $R^{2}, R_{a}^{2}$, for the structural relation (8) for each of the countries in the sample. The break dates $\hat{k}$ and $\hat{k}_{\mathrm{you}}$ have been identified with the Wald statistic described in eq. (4) and are reported in Table 3, panels A and B, respectively. Here, $y$ is the estimated coefficient for the volatility dummy. In the tining colunn, the table displays $S$ if the volatility and return breaks are simultaneous, $B$ if volatility breaks before returns, and $A$ if volatility breaks after returns. Double letters represent a lead-lag of more than 1 year. To conect for heteroscedasticity and autocorrelation in the residuals of the regression, the statistical significance of $\gamma$ is measured using Newey-West standard errors.

a Significant at the $10 \%$ level or less.

in table 3 reflects a more-fundamental interaction between the two underlying hypothesized structures of Section III. Therefore, we estimate the following regression:

$$
\begin{aligned}
v_{t}= & \mu+A v_{t-1}+\sum_{i=1}^{5} b_{i} x_{t+i-3}+d_{t}(\hat{k}) \\
& \times\left[\lambda+\alpha y_{t-1}+\sum_{i=1}^{5} \beta_{i} x_{t+i-3}\right]+\varepsilon_{t}+\gamma d_{t}\left(\hat{k}_{\mathrm{VOL}}\right) .
\end{aligned}
$$

Equation (8) tests whether the statistical power of eq. (1) for a country can be improved by including a dummy for the break in its relation between equity and currency return volatility. In the expression, $d_{t}\left(\hat{k}_{\mathrm{VOL}}\right)$ is equal to zero when $t$ is below the lower limit of the confidence interval for the corresponding volatility break and one otherwise. If volatility shocks were at least partially responsible for break events in returns, we would expect the estimated $\gamma$ values to be statistically significant. Moreover, if such shocks depressed returns, we would expect the estimated $\gamma$ values to be negative. Table 6 reports the results of the estimation of eq. (8). The statistical significance of $\gamma$ is measured using Newey-West standard errors. We include all the countries in the experiment, although for some of them the registered volatility break occurred after the return event. This allows us to check 
the robustness of our analysis. Indeed, when the interval between volatility and return break dates is large and positive, we expect the estimated $\gamma$ values to be insignificant. For example, in the case of Taiwan, where the structural relation between equity and currency volatility breaks almost 1 year after the corresponding return shift, the resulting $\gamma$ is not significantly different from zero.

However, for most the countries in our sample, for which the break in volatility precedes the one in returns, the estimated $\gamma$ values are negative and, in many cases, significant. The exception is South Korea, where $\gamma$ is instead positive but statistically insignificant. That the evidence of a causal relation from volatility to return breaks is weaker for South Korea has two, not necessarily conflicting, explanations. First, the confidence interval around the estimated volatility break date for South Korea (in table 3, panel B) encompasses the events that eventually led the country to abandon its defense of the won, as reported in table 1 . Nonetheless, albeit significant at the $1 \%$ level, the Wald statistic corresponding to such regime shift in the reduced-form volatility relation of eq. (7) is the lowest (and, as is clear from figure 2C, the confidence interval around $\hat{k}$ is the widest) among its East Asian peers, many of which were experiencing more extreme forms of economic and political turmoil at that time. Additionally, the Kospi 200 stock market index managed to recover during the first quarter of 1998 , which is when a break in the linear relation between equity and currency returns is detected (March 1998, in table 3, panel B). This should not be surprising, given that the Korean economy was, and still is, among the most-developed, resilient, and dynamic of the region and given the massive bailout (U.S. $\$ 53$ billion) the country received from the IMF in the fall of 1997 (see Bank for International Settlements 1999 and table 1).

Hence, our evidence is consistent with the results of French et al. (1987) for the U.S. markets. Indeed, in our sample, past regime shifts in the linear relation between equity and currency return volatility appear to have induced a statistically and economically significant decline in equity returns, even after we controlled for the occurrence of a break in the relation between equity and currency returns of eq. (1). In particular, volatility shocks affected future returns for most of the Asian nations that experienced structural shifts in the posited relations between equity and currency markets during 1997 and 1998.

\section{E. Regime Shifts and Information Spillover across Countries}

The preceding analysis suggests not only that, during the events of 1997 and 1998, a negative relationship between volatility and returns characterized many of the Asian countries under investigation but also that the observed sequence of breaks (in table 3 ) appeared to imply a causal link from volatility to returns. An intuitive explanation of this phenomenon is that any information shock that affects the volatility of a single 
market's equity returns, the volatility of the exchange rate, or the relation between the two may eventually induce a shock in returns through the adjustment of the predicted component of the index volatility itself.

Significant cross-country correlations could channel those information shocks from one country into other markets, with market frictions, differences in economic fundamentals, and constraints to hedging influencing the intensity of the spillover phenomenon. The sequential nature of those estimated structural breaks suggests that information spillover effects created return and volatility linkages between Asian markets. Information alters expectations in one market and affects returns and volatility in other markets through changes in hedging demand. The effect of these changes is protracted over time and delayed by the existence of market frictions. The existence of such linkages in East Asia has often been related to the availability of hedging and portfolio rebalancing opportunities among local equity markets around the time of the Asian turmoil. Indeed, Fleming et al. (1998), Kodres and Pritsker (2002), and Pasquariello (2002) contend that portfolio rebalancing represents a major channel for transmitting information shocks across markets. In the remainder of this paper, we address the closely related issues of whether the sequence of breaks reported in Table 3 implies a causal relationship across countries and whether cross-country spillover at or around the time of the Asian turmoil can be attributed to herding behavior by foreign investors.

We use the timing information on the volatility break events contained in table 3, panel B, to explain whether the observed sequence of structural breaks implies their transmission across countries. This evidence suggests that breaks in volatility anticipated breaks in returns and volatility shocks affected future returns for most of the nations that experienced regime shifts in the posited relations between equity and currency markets during the crisis. The timing of the structural breaks in volatility allows us to test for the existence of information spillover by estimating the impact of the break event in country $i$ at time $t$ on the structural relation itself. From table 3, panel B, we identify two sets of countries that experienced a (quasi-) contemporaneous volatility break event. The first set consists of Thailand, Malaysia, and Taiwan in the fall of 1994. The second set comprises Indonesia, South Korea, and the Philippines in 1997-98. We then estimate the regression

$$
\sigma_{y t}=\mu+A \sigma_{y t-1}+b \sigma_{x t}+d_{t}(\hat{k})\left[\lambda+\beta \sigma_{x t}\right]+\sum_{i=1}^{K} \alpha_{i} d\left(\hat{k}_{i}\right) \sigma_{y^{\prime} t}+\varepsilon_{t} .
$$

Equation (9) tests whether the statistical power of eq. (7) can be improved by including a dummy for break dates in the other countries in the group. Therefore, $d\left(\hat{k}_{i}\right)$ is equal to zero when $t$ is below the lower limit of the confidence interval for the volatility break registered in 
TABLE 7 Evaluation of Information Spillover: Volatility

\begin{tabular}{|c|c|c|c|c|c|}
\hline \multirow[b]{2}{*}{ Country } & \multirow[b]{2}{*}{$R_{\pi}^{2}$} & \multicolumn{2}{|c|}{ Contiguous Breaks } & \multicolumn{2}{|c|}{ Spillover Dumny } \\
\hline & & $i=1$ & $i=2$ & $\alpha_{1}$ & $\alpha_{2}$ \\
\hline Malaysia & $96.63 \%$ & Thailand (S) & Taiwan (S) & 0.022 & -0.007 \\
\hline Taiwan & $82.46 \%$ & Malaysia (S) & Thailand (S) & -0.036 & 0.057 \\
\hline Thailand & $95.82 \%$ & Malaysia (S) & Taiwan (S) & $0.188^{c}$ & 0.050 \\
\hline Indonesia & $92.45 \%$ & Philippines (D) & South Korea (D) & $0.042^{\mathrm{b}}$ & $0.262^{\mathrm{b}}$ \\
\hline Philippines & $92.11 \%$ & Indonesia (P) & South Korea (P) & $0.125^{c}$ & -0.021 \\
\hline South Korea & $94.33 \%$ & Philippines (D) & Indonesia (P) & 0.003 & $0.090^{\mathrm{a}}$ \\
\hline
\end{tabular}

NoTE.-This table displays the results of tests for chronologically sequential relations between equity volatility breaks. From table 3, panel B, we identify two sets of countries that experienced a contemporaneous volatility break. The first set consists of Malaysia, Taiwan, and Thailand in mid1994. The second set comprises Indonesia, the Philippines, and South Korea in 1997-98. We then estimate the following regression:

$$
\sigma_{y f}=\mu+A \sigma_{y f-1}+b \sigma_{x f}+d_{f}(\hat{k})\left[\lambda+\beta \sigma_{x f}\right]+\sum_{j=1}^{K} \alpha_{j} d\left(\hat{k}_{i}\right) \sigma_{y f}+\varepsilon_{f}
$$

where $d\left(\hat{k}_{i}\right)$ is equal to zero when $t$ is earlier than the lower limit of the confidence interval for the volatility break registered in county $i$ and one otherwise. The fust column of the table shows the regression adjusted $R^{2}, R_{a}^{2}$, for the structural relationship of eq. (9) for each of the countries in the sample. We identify the break dates $\hat{k}$ and $k$, through the Wald statistic described in eq. (4). Break dates in our sample are collected in table 3 , panel $B$. Country $i$ is where a break contiguous to $\hat{k}$ has been recorded, according to the results reported in table 2. The Contiguous breaks columns display, for each country in the sample, the two markets where a contiguous break was recorded. We use $\mathrm{S}$ if the break is simultaneous, $\mathrm{P}$ if country $i$ breaks before $\hat{k}$, and $\mathrm{D}$ if country $i$ breaks after $\hat{k}$. The last three columns report the corresponding estimated coefficients for the information spillover dummies. To conrect for heteroscedasticity and autocorrelation in the residuals of the regression, the statistical significance of the coefficients is measured using Newey-West standard errors.

Significant at the $15 \%$ level.

Significant at the $10 \%$ level.

c Significant at the $5 \%$ level or less.

country $i$ and one otherwise. If information spillover were at least partially responsible for the propagation of the event from one country to another, we would expect the estimated $\alpha$ values to be statistically significant. Table 7 reports the results of our analysis. Again, we evaluate the statistical significance of the coefficients using Newey-West standard errors. The clustering of volatility breaks in the fall of 1994 does not seem to be characterized by information spillover. Indeed, all the coefficients for break events in other countries are statistically indistinguishable from zero, except for the parameter measuring the propagation of a quasi-contemporaneous volatility shock from Malaysia to Thailand $\left(\alpha_{1}\right.$ in table 7). The results for the second set of countries are strikingly different. Many of the coefficients for other countries' volatility-adjusted break event dummies are significant at the $10 \%$ level or less, in particular suggesting spillover from Indonesia to the Philippines and (more weakly) South Korea. Therefore, the crosscountry propagation variables in table 6 appear to help explain the estimated sequence of volatility breaks occurring in Asia during 1997 
and 1998 and the ensuing statistically and economically significant declines in equity returns.

Prima facie, these findings seem to suggest that, after controlling for past regime shifts in the linear relation between their domestic equity and currency return volatility, Malaysia, Taiwan, and Thailand in the fall of 1994 did not experience spillover of information from other markets in the region, while volatility shocks to Indonesia affected the Philippines and South Korea during the Asian crisis. However, the simultaneity of many of the spillover dummies prevents us from being able to distinguish between a rapid propagation of information innovations from one country to another and a common information shock, and this reduces the statistical power of the analysis of eq. (9). Moreover, such dummies do not explicitly account for one of the possible sources of spillover of information across countries, portfolio rebalancing, nor do they distinguish it from the widespread withdrawal of foreign funds that would accompany a common information shock. Therefore, in the remainder of the paper, we concentrate on the analysis of flows of funds and explore more directly their relationship to the observed sequence of regime shifts between equity and currency markets across the Asian countries in our sample.

\section{Herding, Information Spillover, and Regime Shifts}

While there is general agreement that the Asian crisis was triggered by the devaluation of the Thai baht in July 1997, there is less agreement about the relative significance of the many factors that contributed to its severity. The long-term consequences of the Asian crisis, the role of foreign investment, and the manner in which the crisis propagated across the economies of Asia indeed remain hotly debated issues among academics and practitioners. ${ }^{20}$ However, the most frequently mentioned culprit for the crisis is the destabilizing effect of the flight of foreign capital from financially integrated markets. In particular, much popular press blames the "excessive speculation" and rapid withdrawal of capital by hedge funds for the events of 1997 and 1998 . Although many studies suggest that portfolio rebalancing may have represented a major channel for transmitting information shocks across markets during the Asian crisis, the available empirical evidence remains inconclusive. In the remainder of this paper, we attempt to clarify some important aspects of the crisis through a formal analysis of the impact of flows of capital in Indonesia, Malaysia, the Philippines, South Korea, Taiwan, and Thailand on the relation between their equity and foreign exchange markets.

20. Kallberg, Liu, and Pasquariello (2002) present an overview of the main explanations proposed by the economic and financial literature. For a further discussion of the causes of the Asian crisis, refer to Gangnes (1998) and Wu (1998). 


\section{A. Herding and Regime Shifts}

We start by investigating the herding behavior of foreign investors. Capital flight, in particular the widespread withdrawal of foreign funds from emerging equity markets, appears to have played an important role in the Asian crisis, especially in creating pressure on the domestic currencies and interest rates. Herding occurs when different markets simultaneously (or with only a slight lag) experience flows of foreign capital in the same direction. Herding intensifies the transmission of single-market information shocks through geographically or fundamentally heterogeneous markets. In our analysis, intercountry herding can arise because of distinct, yet related reasons, as in Wermers (1999). First, managers might mimic each other's behavior, disregarding their private information, to avoid jeopardizing their reputation by trading differently from other managers, who are acting in apparently interrelated markets. Second, managers might make country allocation decisions simultaneously. This could happen either because the original information shock affecting a single market is correlated to the information sets of the other markets or because a common information shock simultaneously affects all the information sets. Third, managers could infer private information from observing trading in geographically heterogeneous markets. Finally, institutional investors trading in different markets might need to rebalance their aggregate holdings in these markets as a result of global portfolio reallocation.

To evaluate the extent to which international portfolio managers reallocated their wealth across the region, we use time series data on the net monthly flow of funds in each equity market. The flow is the difference (in millions of U.S. dollars) between total foreign purchases and sales of domestic equities in each month. Flow of funds data were collected by local stock market authorities and made available to us by a major investment bank. Sample periods in most cases overlap the ones for equity and currency data and, again, all end in March 1999. Summary statistics for this data set are reported in table 2. Flows of funds show great variation across the sample, although the means are positive for each country. ${ }^{21}$ Figures $2 \mathrm{c}$ and $3 \mathrm{c}$ display our monthly flows

21. A word of caution on the use of such data is necessary. The difference between total foreign purchases and sales of domestic equities in each month accounts only for the trading activity of foreign investors in the domestic spot equity markets. Speculative forces can nonetheless deeply affect financial markets even while inducing little or no change in those flows of funds. For example, our data set ignores the flow of loans from foreign banks to domestic borrowers that, as previously mentioned, characterized many East Asian economies during the early 1990s. Furthermore, if speculators choose to trade in derivatives (like swaps) to take a negative stance on a particular country, thus exercising a downward pressure on the corresponding domestic markets, their actions would cause only marginal fluctuations in the flows of funds to that country. Unfortunately, evidence on such activity is too scant, and often just anecdotal, to be employed in the statistical analysis that follows. We thank an anonymous referee for these observations. 
of funds data for Indonesia, Malaysia, the Philippines, South Korea, Taiwan, and Thailand over two time intervals, March-December 1997 and January-October 1998. These two intervals correspond to most of the observed break dates for equity versus currency returns (figures $2 a$ and $3 a$ ) and equity versus currency return volatility (figures $2 b$ and 3b).

The observed pattern in the flows of funds for 1997 (in figure 2c) is striking. Intense portfolio rebalancing activity occurred during the selected time period. While Malaysia suffered the most significant outflows, countries such as South Korea, the Philippines, and even Thailand experienced inflows of capital for most of that summer. These findings, coupled with the evidence that most of the volatility shocks accompanying the Asian crisis (in table 3, panel B) occurred between August and October 1997, are consistent with information spillover effects. Portfolio rebalancing appears to be a major channel by which information shocks were transmitted across markets during 1997. The picture for 1998 (figure 3c) is not as clear. Most of the countries in our sample experienced significant contemporaneous inflows and outflows of capital at that time, with Malaysia again acting as the bellwether. This is when our empirical model identifies structural breaks in the hypothesized return relations. In this case, figure $3 \mathrm{c}$ seems to suggest that portfolio reallocation efforts affected the entire region during 1998, although with a different intensity for each market, that is, herding may have been a driving force for the events of that year.

To ascertain the statistical significance of these considerations, we use a measure of herding developed by Lakonishok, Shleifer, and Vishny (1992) and adopted by Wermers (1999). Choe, Kho, and Stulz (1999) employ a similar criterion to analyze herding behavior in the Korean stock market in 1997. The herding measure for a given month $t$, $H(t)$, is defmed as

$$
H(t)=\left|b(t)-E_{t-1}[b(t)]\right|-E\left\{\left|b^{*}(t)-E\left[b^{*}(t)\right]\right|\right\} ;
$$

where $b(t)$ is the number of countries in which we observe negative flows of funds divided by the total number of countries for which flows of funds were available at time $t$.

Equation (10) implies that either sign of $H(t)$ is equally likely. The proxy for $E_{t-1}[b(t)]$, the expected proportion of oufflows during a given month, is the simple average of the observed $b(t)$ during the past quarter. We calculate the adjustment term $E\left\{\mid b^{*}(t)-E\left[b^{*}(t)\right]\right\}$ under the null hypothesis that herding is observed only as a result of random chance. Hence, $b^{*}(t)$ is the proportion of negative flows that we would observe by drawing $x_{t}$, the number of observed outflows at time $t$, from a binomial distribution $B\left(x_{t}, n_{t}\right)$, where the probability of a single sell outcome is one half and $n_{t}$ is the number of countries in the 
TABLE 8 Analysis of the Average Herding Measure, $H(t)$, for Selected Periods

\begin{tabular}{lcccc}
\hline Periods & Mean $H(t)$ & Median $H(t)$ & Std Dev $H(t)$ & $t$-Statistic \\
\hline $5 / 93-3 / 99$ & $6.55 \%$ & $6.25 \%$ & $19.07 \%$ & $2.83^{\mathrm{b}}$ \\
$5 / 93-12 / 95$ & $6.99 \%$ & $6.25 \%$ & $19.85 \%$ & $1.90^{\mathrm{a}}$ \\
$1 / 96-12 / 97$ & $2.05 \%$ & $-4.51 \%$ & $13.95 \%$ & 72 \\
$1 / 98-3 / 99$ & $12.89 \%$ & $12.15 \%$ & $23.56 \%$ & $2.12^{\mathrm{a}}$ \\
\hline
\end{tabular}

NoTE.-This table displays the results of tests for the null hypothesis that herding is observed in selected time periods only by random chance; that is, the average herding measure $H(t)$ developed by Lakonishok et al. (1992) has mean equal to zero across the six countries in our sample; Indonesia, Malaysia, the Philippines, South Korea, Tajwan, and Thailand. We compute $H(t)$ as

$$
H(t)=\left|b(t)-E_{\tau-1}[b(t)]\right|-E\left\{\left|b^{*}(t)-E\left[b^{*}(t)\right]\right|\right\}
$$

where $b(t)$ is the number of countries in which we observe negative flows of funds over the total number of flows of funds available at time $t$. Flows of funds are in millions of U.S. dollars and are calculated as the difference between the total foreign purchases and sales of domestic stocks in each month of the sample. The proxy for $E_{f-1}[b(t)]$, the expected proportion of sellers during a given month, is the simple average of the observed $b(t)$ during the preceding quarter. The adjustment temm $E\left\{\left|b^{*}(t)-E\left[b^{*}(t)\right]\right|\right\}$ is calculated under the null hypothesis that herding is observed only as a result of random chance. Hence, $b^{*}(t)$ is the proportion of negative flows we would observe by drawing $x_{f}$, the number of observed outflows at time $t$, from a binomial distribution $B\left(x_{t}, n_{t}\right)$, where the probability of a single sell outcome is one half and $n_{t}$ is the number of countries in the sample for which flows of funds data were available at time $t$. Since $x_{t}$ follows a binomial distribution with probability $b^{*}(t)$ of success, $E\left\{\left|b^{*}(t)-E\left[b^{*}(t)\right]\right|\right\}$ easily follows given $b^{*}(t)$ and $n_{\tau}$. Our final measures of herding are generated as averages of $H(t)$ over selected time intervals.

Significant at the $10 \%$ level.

th Significant at the $1 \%$ level or less.

sample for which flows of funds data were available at time $t$. Since $x_{t}$ follows a binomial distribution with probability $b^{*}(t)$ of success, $E\left\{\left|b^{*}(t)-E\left[b^{*}(t)\right]\right|\right\}$, is then easily calculated given $b^{*}(t)$ and $n_{t}$. Our final measures of herding are averages of $H(t)$ over selected time intervals.

When we analyze the herding measure for the chosen sample subperiods, we can test for systematic patterns in the aggregate behavior of fund managers who invest in the Far East. Any significant value of $H(t)$ signals that international investors tend to trade in different markets together, at the same time, and in the same direction more often than would be expected by random and independent trading.

Table 8 reports summary results on the herding measure $H(t)$ for four time intervals. Over the longest time period, from May 1993 (when we have flows of funds for at least three countries) to March 1999, the figures are significant at the $1 \%$ level, indicating the presence of herding behavior. Breaking the time period into three subperiods shows that herding occurred primarily during 1998 and early 1999 , when the $t$-statistic for $H(t)$ is significant at the $10 \%$ level. In the interval surrounding the Mexican peso crisis, between 1993 and the end of 1995 , evidence of herding in our sample of Asian markets is weaker. In 1996 and 1997, the herding measure is instead barely different from zero, as is the corresponding $t$-test. These results suggest that, consistent with the 
analysis of figures 2 and 3, herding was strongest in 1998, the period during which most regime shifts in returns occurred.

\section{B. Herding and Chistering of Break Events}

One of the most puzzling characteristics of the financial crises of the past decade is the speed at which they appear to move from one country to the other, as the results of our investigation into how currency and equity markets interact during stress periods seem to confirm. As previously mentioned and as evident from the upper panels of figures 2 and 3 , breaks in the relation between currency and equity returns and return volatility are concentrated in relatively short periods of time, even after we account for the statistical uncertainty surrounding our estimates. Figures 2 and 3 and table 8 make it apparent that capital-flow reversals from international investors played a significant role in the clustering of estimated breaks in the reduced-form relations of eqq. (1) and (7) across Asian countries during 1997 and 1998. This should not be surprising, given the large holdings of emerging markets' publicly available equity by international investors and the mounting evidence of institutional panic and herding around the time when the crises occurred. Most significant for our paper, Kaminsky, Lyons, and Schmukler (2001) observe that mutual fund investments were very responsive and volatile during most of the crises of the $1990 \mathrm{~s}$. In particular, they argue that the events of 1997 and 1998, although initiated in a single country (Thailand and Russia, respectively), rapidly propagated to other markets, due to the large and widespread withdrawals of funds from Asia, Latin America, and Eastern Europe, thus providing support for cross-country spillover effects. In this section, we explore this issue in more depth. In the analysis we presented so far, breaks in the estimated relations between equity and currency return volatility cluster over a few months of 1997 , when, however, the herding measure $H(t)$ was barely different from zero. Breaks in the reduced-form relation between equity and currency returns were instead concentrated in 1998, when $H(t)$ was instead large and significant. This evidence seems to suggest that herding played a role in the clustering of return breaks but less so in the clustering of volatility breaks.

To translate this intuition into a more rigorous statistical investigation, we define some new variables. The first is $I_{t}$, the number of countries that at time $t$ are experiencing a statistically significant break in their reduced-form relation between equity and currency markets; more specifically, $I_{t}$ is the number of countries for which $t$ falls in the corresponding break confidence interval, as specified in table 3 . Hence, $I_{t}$ measures the extent of the concentration of break events across the countries in our sample for each period $t$. We compute $I_{t}$ for the sequences of both return breaks and return volatility breaks. In the remainder of this section, we test whether herding explains the variability 
of these series, which proxy for the clustering of volatility or return break events.

To that end, we use the flows of funds data described in section II to derive a measure of the intensity of the herding behavior of international investors at each point in time $t$. We define $H M_{1 t}$ as the number of countries that at time $t$ were experiencing a net outflow of funds from international investors. ${ }^{22} H M_{1 t}$ is a measure of signed herding, therefore focusing on the extent of net withdrawals across Asia at each point in time, which Kaminsky et al. (2001) already identified as a likely culprit in the events of 1997 and 1998.

We test whether the herding proxy $H M_{1 t}$ can explain the clustering of the break events reported in table 3 . The easiest approach would be to use linear regressions. However, because the break is, by construction, a unique event and these events are concentrated over relatively few dates, the discrete variables $I_{t}$ for returns and volatility are characterized by a preponderance of zeros and small values. Hence, such data appear to be better analyzed by a specification that accounts for those properties. In particular, the econometric literature suggests the use of the Poisson regression model.

According to this approach, each variable $I_{t}$ is assumed to be drawn from a Poisson distribution with parameter $\lambda_{t}$. The model is then

$$
\operatorname{Pr}\left(I_{t}=i\right)=\frac{e^{-\lambda_{s}} \lambda_{t}^{i}}{i !} \quad i=0,1,2, \ldots
$$

where $i$ is the number of countries experiencing a break event at time $t$. The variable $\lambda_{t}$ is related to the signed herding regressor $H M_{1 t}$ in terms of a $\log$-linear model; that is, $\ln \lambda_{t}=B^{\prime} R_{t}$, where $B=[$ constant, $\beta]$ and $R_{t}=\left[1, H M_{1 t}\right]^{23}$ We estimate the model of eq. (11) by maximum likelihood for the full sample Jan 1992-Mar 1999. Our parameter of interest is clearly $\beta$. If estimates of $\beta$ are positive and significant, then the expected number of break events per period $E\left[I_{t} \mid H M_{1 t}\right]$ is bigger and the clustering of break events more likely when herding is more intense (i.e., when $H M_{1 t}$ is higher). It is easy to show that the partial derivative of the conditional expected number of break events per period $E\left[I_{t} \mid H M_{1 t}\right]$ with respect to the corresponding herding measure is given by $\lambda_{t} \beta$. In table 9 , we report the results of the estimation of eq. (11) for $I_{t}$ computed with respect to the breaks in the reduced-form eq. (7) for return volatility (listed in

22. As previously mentioned, our data set covers net purchases (or sales) by foreign investors in the domestic spot equity markets for each of the six countries in our sample. However, although such data start on January 1992, both equity retun and flows data are simultaneously available for all six countries only from March 1996. To accommodate these limitations, the variables $I_{t}$ and $H M_{1}$ are computed using only the subset of countries for which both flows of funds data and regime shift information were available at time $t$.

23. For more on this topic, see Greene (1997), especially chapter 19. 
TABLE 9 Herding and Spillover Effect: Poisson Model for Clustering of Breaks

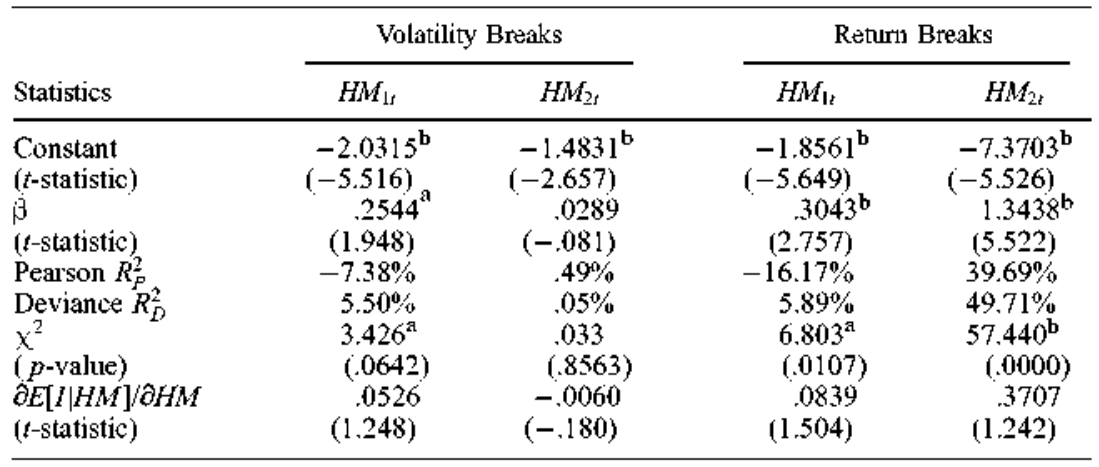

Note.-This table displays the results of the estimation of the Poisson regression model for the number of simultaneous break events in each period $t, I_{f}$, computed using the confidence intervals for breaks reported in table 3 , panel $\mathrm{B}$ (for equity versus curency return volatility) and table $\hat{3}$, panel A (for equity versus currency retums). The probability of $i$ such events in period $t$ is given by

$$
\operatorname{Pr}\left(I_{t}=i\right)=\frac{e^{-\lambda_{i}} \lambda_{t}^{i}}{i !} \quad i=0,1,2 \ldots
$$

The variable $\lambda_{\mathrm{f}}$ is formulated in teims of a $\log$-linear model, i.e., $\ln \lambda_{\mathrm{f}}=B^{\prime} R_{\mathrm{f}}$, where the coefficient vector $B=$ [constant, $\beta] ; H M_{1 z}$ and $H M_{2 z}$ are the measures of signed and unsigned herding, respectively, described in the text; and $R_{f}=\left[1, H M_{1 f}\right]$ or $R_{f}=\left[1, H M_{2 f}\right]$. The model of eq. (11) is estimated via maximum likelihood. For each of the estimated coefficients (the constant and the herding paraneter B) we report the corresponding $t$-statistic. The two $R^{2}$ statistics help assess the improvement of the fit resulting from using $\lambda_{r}$ instead of the mean value for $y$ to predict $l_{f}$. The Pearson $R_{P}^{2}$ is computed as $R_{p}^{2}=1-\left[\Sigma_{t}\left(I_{t}-\lambda_{t}\right)^{2} / \lambda_{t}\right] /\left[\Sigma_{\tau}\left(I_{t}-I_{\mathrm{bar}}\right)^{2} / I_{\text {bar }}\right]$, where $I_{\mathrm{bar}}$ is the mean of $I_{t}$ over the sample. The Deviance $R_{D}^{2}$ is instead obtained as $R_{D}^{2}=1\left[\Sigma_{f} I_{f} \ln \left(I_{f} / \lambda_{f}\right)\right] /\left[\Sigma_{f} I_{f} \ln \left(I_{f} / I_{\text {bat }}\right)\right]$. The goodness-of-fit statistics $x^{2}$ tests the hypothesis that the coefficients of the regression in eq. (11) are all zero. We also repont the partial derivative of the conditional expected number of break events per period $E\left[I_{s} \mid H M_{1 s}\right]$ with respect to the corresponding herding measure, $H M_{l}$ This measure, given by $\lambda_{r} \beta$, is computed at the mean of $H M_{1 s}$. The clustering measure is computed using the six countries in our sample: Indonesia, Malaysia, the Philippines, South Korea, Taiwan, and Thailand. The model is estimated over the interval from January 1992 to March 1999.

a Significant at the $10 \%$ level.

bignificant at the $1 \%$ level or less.

table 3, panel B) and with respect to the breaks in the reduced-form eq. (1) for return (listed in table 3, panel A).

The results from table 9 support our initial hypothesis that signed herding was a relevant factor in explaining the estimated clustering of return break events during 1998. In the third column of table 9, the coefficient $\beta$ is positive and statistically significant at the $1 \%$ confidence level, as is the chi-squared statistic. Interestingly, signed herding appears to have played an important role in the clustering of volatility break events observed in 1994 (as hinted by table 3, panel B) and 1997 as well. Indeed, the estimated coefficient $\beta$ is again positive and significant, although the evidence for the model's fit is less compelling.

We perform a parallel analysis using an alternative, more general measure of herding, $H M_{2 t}$, defined as the maximum of $H M_{1 t}$ and the number of countries that at time $t$ were experiencing a net inflow of 
funds from international investors. $H M_{2 t}$ is a proxy for unsigned herding, because it captures the extent to which international investors in different countries act together, independent of the direction of their flows. We estimate eq. (11) using $H M_{2 t}$ for both return- and volatilitybased $I_{t}$ Unsigned herding appears to explain the concentration of regime shifts in returns but not the clustering of return volatility breaks during both the Mexican peso and the Asian crises. Indeed, the model for volatility (in the second column of table 9) is clearly rejected by the data. Nonetheless, unsigned herding significantly improves the fit of eq. (11) with respect to the clustering of return breaks, generating two different $R^{2}$ values between $40 \%$ and $50 \% .{ }^{24}$ Furthermore, using the estimates for $\beta$ in the fourth column of table 9 to compute $\lambda_{t} \beta$ over the mean values for $R_{t}$, we find that, on average, about one additional country suffers a regime shift in the reduced-form return relation of eq. (1) when the number of countries experiencing flows of funds of the same sign increases by 3 units. ${ }^{25}$

To provide more intuition for these results, in figure 4 , we plot the probabilities for various outcomes of the clustering variable $I_{t}$, for $I_{t}=0,1,2$, and 3 , computed according to the following recursion:

$$
\begin{aligned}
& P_{t}^{0}=\operatorname{Pr}\left(I_{t}=0\right)=e^{-\lambda_{t}} \\
& P_{t}^{i}=\operatorname{Pr}\left(I_{t}=i\right)=\left(\frac{\lambda_{t}}{i}\right) P_{t}^{i-1} \quad i=1,2,3 .
\end{aligned}
$$

The probabilities in eq. (12) are estimated using the coefficients from the first and third columns of table 9 , for both the measures of volatility break clustering (figure $4 a$ ) and return break clustering (figure 4b), together with the corresponding dependent variable itself and the signed herding measure $H M_{1 t}$ The correlation between those $I_{t}$ values and $H M_{1 t}$ is evident. As a consequence of the good fit provided by the model of eq. (11), the probability of no regime shifts drops, the expected number of countries suffering a break increases, and the clustering probabilities $P_{t}^{2}$ and $P_{t}^{3}$ rise significantly when signed herding is more intense, that is, when the percentage of funds' outflows across Asian equity markets is higher.

In short, our analysis suggests that the likelihood of observing a concentration of regime shifts is an increasing function of signed herding, that is, widespread withdrawals from the corresponding equity markets; unsigned herding appears to be less successful in explaining the

24. More precise definitions of the two different $R^{2}$ values used to measure the fit of the log-linear model are in the note to table 9.

25 . In table 9 , however, none of these measures is statistically significant, even though $\beta$ is, because of the standard errors of the mean regressors. 
A) Volatility Breaks Clustering

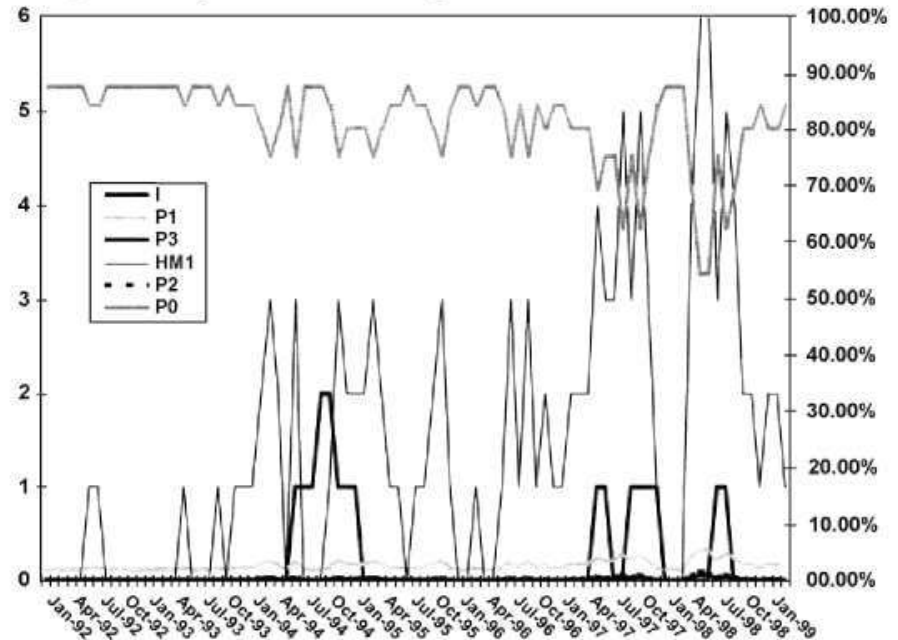

B) Return Breaks Clustering

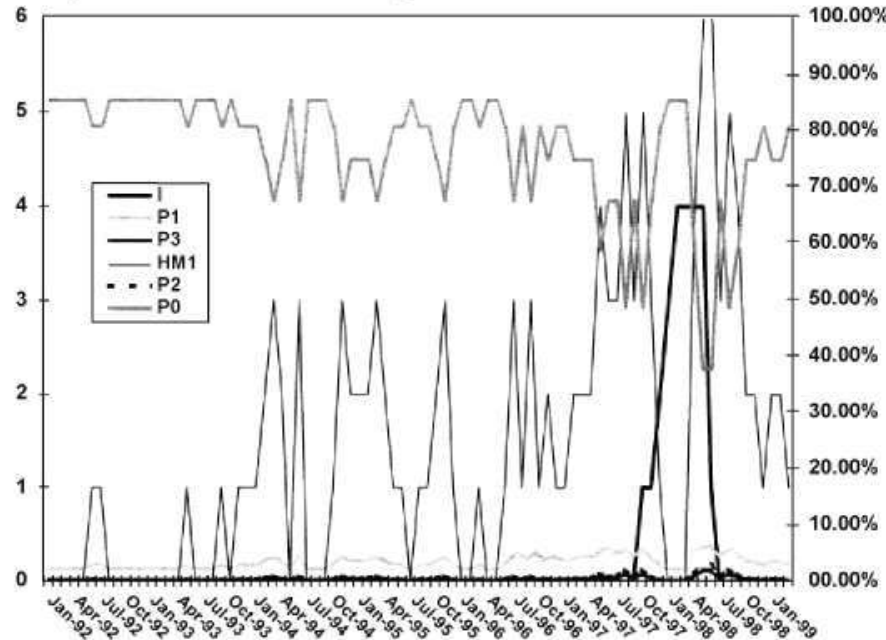

Fig. 4.-Probabilities of clustering of break events: Volatility and return. Figure 4 displays the time series of probabilities for the following outcomes of the clustering variable $I_{t}=0,1,2$, and 3 , computed according to the recursion

$$
\begin{aligned}
& P_{t}^{0}=\operatorname{Pr}\left(I_{t}=0\right)=e^{-\lambda_{t}} \\
& P_{t}^{i}=\operatorname{Pr}\left(I_{t}=i\right)=\left(\frac{\lambda_{t}}{i}\right) P_{t}^{i-1} \quad i=1,2,3,
\end{aligned}
$$

for both the series of volatility breaks (figure $4 \mathrm{a}$ ) and the series of breaks in returns (figure $4 \mathrm{~b}$ ), using the estimates for the constant term and the herding coefficient $\beta$ for $\mathrm{HM}_{1 \mathrm{t}}$ from table 9 and the $\log$-linear model $\ln \lambda_{t}=B^{\prime} R_{t}$ where $B=[$ constant, $\beta]$ and $R_{t}=\left[1, H M_{1 t}\right]$. On the left axis, we plot (dark line) the number of simultaneous breaks $I_{t}$ and (thin line) the explanatory variable $H M_{1 t}$, while on the right axis we plot $P_{t}^{0}$, $P_{t}^{1}, P_{t}^{2}$, and $P_{t}^{3}$. 
clustering of return volatility breaks during 1994 and 1997 . These findings are consistent with our previous assertion that, as a result of herding behavior by international investors, the Asian financial markets experienced cross-country spillover during the crisis.

\section{Conclusions}

Foreign exchange markets played a central role in the events that occurred in Asia in 1997 and 1998. Our study investigates the structural relation between currency and equity markets in six Asian countriesIndonesia, Malaysia, the Philippines, South Korea, Taiwan, and Thailandaround the time of the crisis. For each country, we specify reducedform linear relations between equity index returns and lead-and-lag currency returns. We chose the lead-and-lag specification to allow the data to determine whether and how one market anticipates or follows another. We adopted similar specifications to describe the structural relation between equity and currency return volatility. We applied the nonparametric statistical technique of Bai, Lumsdaine, and Stock (1998) to test for the existence of a single structural break in the posited relations between the time series of equity and currency returns and return volatility, respectively. We also computed confidence intervals for the estimated break dates for each country.

We found that statistically and economically significant regime shifts in those relations did indeed take place in each of the countries in our data set over the sample period. The estimated regime shifts between equity and currency returns differ widely, both in timing and nature, from country to country. The shocks in the return relations appear to affect Malaysia and South Korea first, in early 1998, then move to the rest of Asia. Volatility breaks instead cluster during the Mexican peso crisis, in the fall of 1994, for Malaysia, Taiwan, and Thailand, and at the time of the first Asian currency crisis, in the last months of 1997, for the other countries in our sample. Our analysis shows that, for many of the countries in the sample, the corresponding domestic equity markets became more responsive to the volatility in currency markets after the regime breaks.

We used the chronology of breaks implied by our analysis to distinguish whether market linkages among countries are due to common information shocks or information spillover effects. Most of the estimated breaks in the hypothesized return and return volatility structural relations are not simultaneous, even when the uncertainty surrounding our estimates is taken into account. The sequential nature of these regime shifts indicates that information spillover effects created linkages across the Asian markets during 1997 and 1998. Information alters expectations in one market and affects returns and volatility in other markets through changes in hedging demand. The effect of these 
changes is protracted over time and delayed by the existence of market frictions.

We examined the related issue of whether the negative relation between volatility and returns found by French et al. (1987) for the U.S. market holds for Asian markets. We found not only that there is a negative relationship between volatility and returns in the data but also that the breaks in volatility appear to have anticipated the breaks in returns. Moreover, the observed sequence of breaks appears to imply a causal relationship from volatility to returns. We in fact show that past volatility shocks negatively affected future returns for most of the nations that experienced regime shifts in the posited relations between equity and currency markets during the crisis.

We further tested whether the estimated sequence of breaks implies a causal relationship across countries. Our analysis shows no evidence of information spillover for Malaysia, Taiwan, and Thailand in 1994, when they experience a simultaneous volatility break event. A common information shock seems a more likely explanation for the set of volatility breaks that occurred in those countries. We found instead some evidence of information spillover across Indonesia, the Philippines, and South Korea between 1997 and 1998.

Many studies argue that herding behavior and the trading activity of international investors represent major channels for transmitting information shocks across markets. In that respect, our analysis suggests that portfolio rebalancing played a crucial role during 1997 but not in 1998. We also found evidence of herding behavior over the entire sample period. The lowest degree of herding occured between 1996 and 1997, when most of the breaks in volatility were observed; herding was particularly intense in 1998, around the time when most of the breaks in the posited reduced-form return relations were detected.

Finally, using a Poisson regression model, we provide additional support for the hypothesis that the Asian markets were affected by cross-country spillover at or around the time of the crisis, by showing that the expected number of return and return volatility break events per period was bigger, and the clustering of those break events more likely, when signed herding was more intense, that is, when more equity markets were simultaneously experiencing funds' withdrawals.

\section{References}

$\rightarrow$ Allen, F, and D. Gale. 2000. Financial contagion. Journal of Political Economy 108:1-33. Andersen, T., T. Bollerslev, F. Diebold, and P. Labys. 1999. The distribution of exchange rate volatility. Working paper, Stern School of Business, New York University.

Baig, T., and 1. Goldfajn. 1998. Financial market contagion in the Asian crisis. Working paper, International Monetary Fund, Geneva.

$\rightarrow$ Bai, J., R. Lumsdaíne, and J. Stock. 1998. Testing for and dating common breaks in multivariate time series. Revien of Economic Studies 65:395-432. 
Banerjee, A., R. Lumsdaine, and J. Stock. 1992. Recursive and sequential tests of the unit root and trend break hypothesis. Journal of Business and Economic Statistics 10:271-88.

Bank for International Settlements. 1999. A review of financial market events in autumn 1998. Bank for International Settlements. Basel.

Bekaert, G., C. Harvey, and R. Lumsdaine. 2002a. Dating the integration of world equity markets. Journal of Financial Economics 65:203-47.

Bekaert, G., C. Harvey, and R. Lumsdaine. 2002b. The dynamics of emerging market equity flows. Journal of International Money and Finance 21:295-350.

Bertero, E., and C. Mayer. 1990. Structure and performance: global interdependence of stock markets around the crash of October 1987. European Economic Review 34:1155-80.

Bollerslev, T., R. Chou, and K. Kroner. 1992. ARCH modeling in finance: A review of the theory and empirical evidence. Journal of Econometrics 37:231-56.

Brown, K., W. Harlow, and S. Tinic. 1993. The risk and required return of common stock following major price innovations. Journal of Financial and Quantitative Analysis 28:101-16.

Buiter, W., G. Corsetti, and P. Pesenti. 1998. Financial markets and European monetary cooperation: The lessons of the 1992-1993 exchange rate mechanism crisis. Studies in International Finance, 84, Princeton University.

Calomiris, C. 1995. Financial fragility: Issues and policy implications. Journal of Financial Services Research 9:241-57.

Calvo, G., and E. Mendoza. 1997. Rational herd behavior and the globalization of securities markets. Unpublished discussion paper, Federal Reserve Bank of Minneapolis.

Chancellor, E. 2000. Devil take the hindmost: A history of financial speculation, 2nd ed. New York: Farrar, Straus and Giroux.

Choe, H., B. Kho, and R. Stulz. 1999. Do foreign investors destabilize stock markets? The Korean experience in 1997. Journal of Financial Economics 54:227-64.

Corsetti, G., P. Pesenti, and N. Roubini. 1998. What caused the Asian currency and financial crisis? Working paper, Yale University.

Dasgupta, A. 2000. Regionality revised: An examination of the direction of spread of currency crises. Working paper, Yale University.

Edwards, S., and R. Susmel. 2000. Interest rate volatility and contagion in emerging markets: Evidence from the 1990's. Working paper 7813, National Bureau of Economic Research, Cambridge, MA.

Edwards, S., and R. Susmel. 2001. Volatility dependence and contagion in emerging equity markets. Working paper 8506, National Bureau of Economic Research, Cambridge, MA.

$\rightarrow$ Eichengreen, B., A. Rose, and C. Wyplosz, C., 1996. Contagious currency crises: First tests. Scandinavian Journal of Economics 98:463-84.

Fleming, J., C. Kirby, and B. Ostdiek. 1998. Information and volatility linkages in the stock, bond and money markets. Journal of Financial Economics 49:111-37.

$\rightarrow$ Forbes, K., and R. Rigobon. 2002. No contagion, only interdependence: Measuring stock market co-movements. Journal of Finance 57:2223-61.

$\rightarrow$ French, K., W. Schwert, and R. Stambaugh. 1987. Expected stock returns and volatility. Journal of Financial Economics 19:3-29.

Gangnes, B. 1998. The Asian crisis: Toward recovery and reform. Report on a United Nations Expert Group Meeting, Department of Economic and Social Affairs, New York, March 17-18, 1998.

Glick, R., and A. Rose. 1999. Contagion and trade: Why are currency crises regional? Journal of International Money and Finance 18:603-17.

Greene, W. 1997. Econometric analysis, 3rd ed. Englewood Cliffs, NJ: Prentice-Hall.

Grier, K., and R. Grier. 2001. Exchange rate regimes and the cross-country distribution of the 1997 financial crisis. Economic Inquiry 39:139-47.

$\rightarrow$ Hamao Y., R. Masulis, and V. Ng. 1990. Correlations in price changes and volatility across international stock markets. Review of Financial Studies 3:281-307.

Hamilton, J., and R. Susmel. 1994. Autoregressive conditional heteroskedasticity and changes in regime. Journal of Econometrics 64:307-33.

$\rightarrow$ Harvey, C. 1995. Predictable risk and returns in emerging markets. Review of Financial Studies 8:773-816.

$\rightarrow$ Haugen, R., E. Talmor, and W. Torous. 1991. The effect of volatility changes on the level of stock prices and subsequent expected returns. Journal of Finance 46:985-1007. 
Hirshleifer, D., A. Subrahmanyam, and S. Titman. 1994. Security analysis and trading patterns when some investors receive information before others. Journal of Finance 49:1665-98.

Kallberg, J., C. Liu, and P. Pasquariello. 2002. An examination of the Asian crisis part II: Information spillover, herding, and regime shifts. Working paper, Stern School of Business, New York University.

Kaminsky, G., and C. Reinhart. 2000. The center and the periphery: Tales of financial turmoil. Working paper, University of Maryland.

Kaminsky, G., R. Lyons, and S. Schmukler. 2001. Mutual fund investment in emerging markets: An overview. Working paper, George Washington University.

$\rightarrow$ Karolyi, A., and R. Stulz. 1996. Why do markets move together? An investigation of U.S.-Japan stock return co-movements. Journal of Finance 51:951-86.

$\rightarrow$ Kodres, L. E., and M. Pritsker. 2002. A rational expectations model of financial contagion. Journal of Finance 57:769-99.

Lakonishok, J., A. Shleifer, and R. Vishny. 1992. The impact of institutional trading on stock prices. Journal of Financial Economics 32:23-44.

Lee, S., and K. Kim. 1993. Does the October 1987 crash strengthen co-movements among international stock markets? Review of Financial Economics 3:89-102.

Lin, W., and A. Kuo, 2000. An overview of the East Asian financial crisis. Review of Pacific Basin Financial Markets and Policies 3:107-20.

Merton, R. 1980. On estimating the expected return on the market: an exploratory investigation. Journal of Financial Economics 8:323-61.

Obstfeld, M. 1998. The global capital market: Benefactor or menace? Working paper, University of California, Berkeley.

$\rightarrow$ Officer, R. 1973. The variability of the market factor of New York Stock Exchange. Journal of Business 46:434-53.

Park, Y., and J. Lee. 2001. Recovery and sustainability in East Asia. Working paper 8373, National Bureau of Economic Research, Cambridge, MA.

Pasquariello, P. 2002. Imperfect competition, information heterogeneity, and financial contagion. Working paper, Stern School of Business, New York University.

$\rightarrow$ Perron, P. 1989. The great crash, the oil price shock and the unit root hypothesis. Econometrica 57:1361-1401.

Picard, D. 1985. Testing and estimating change-points in time series. Advances in Applied Probability 176:841-67.

Quandt, R. 1958. The estimation of the parameters of a linear regression system obeying two separate regimes. Journal of the American Statistical Association 53:873-80.

$\rightarrow$ Quandt, R. 1960. Tests of the hypothesis that a linear regression system obeys two separate regimes. Journal of the American Statistical Association 55:324-30.

Renaud, B. 1997. The 1985 to 1994 global real estate cycle: An overview. Journal of Real Estate Literature 5:13-44.

Renaud, B. 1999. Real estate and the Asian crisis: Lessons of the Thailand crisis. Capital Markets Development Department, World Bank, Geneva.

Rigobon, R. 2001. Contagion: How to measure it? Working paper 8118, National Bureau of Economic Research, Cambridge, MA.

$\rightarrow$ Shalen, C. 1993. Volume, volatility and the dispersion of beliefs. Review of Financial Studies 6:405-34.

Susmel, R. 2000. Switching volatility in international equity markets. International Journal of Finance and Economics 5:265-83.

$\rightarrow$ Tauchen, E., and M. Pitts. 1983. The price-variability-volume relationship on speculative markets. Econometrica 51:485-506.

Thurow, L. 1998. The collapse and the cure. The New York Review of Books (February 5).

$\rightarrow$ Wermers, R. 1999. Mutual fund herding and the impact on stock prices. Journal of Finance $54: 581-622$.

Wu, R. I. 1998. Taiwan's role in the Asian financial crisis. Working paper, Taiwan Institute of Economic Research. 